\title{
A crosstalk between CAR T cell subsets and the tumor microenvironment is essential for sustained cytotoxic activity
}

Morgane Boulch ${ }^{1,2, *}$, Marine Cazaux ${ }^{1,2,{ }^{*}}$, Yann Loe-Mie ${ }^{3}$, Ronan Thibaut ${ }^{1}$, Béatrice Corre ${ }^{1}$, Fabrice Lemaître ${ }^{1}$, Capucine L. Grandjean ${ }^{1}$, Zacarias Garcia ${ }^{1}$ and Philippe Bousso ${ }^{1}$

1 Dynamics of Immune Responses Unit, Equipe Labellisée Ligue Contre le Cancer, Institut Pasteur, INSERM U1223, 75015 Paris, France.

${ }^{2}$ University Paris Diderot, Sorbonne Paris Cité, Paris, France.

3 Institut Pasteur, Hub Bioinformatique et Biostatistique, Département de Biologie Computationnelle (USR 3756 IP CNRS), Paris, France.

* These authors contributed equally to this work

Correspondence to marine.cazaux@aphp.fr or philippe.bousso@pasteur.fr

One-sentence summary: A crosstalk involving CAR T cell-derived IFN- $\gamma$ and hostderived IL-12 is essential to maintain CAR T cell killing potential in vivo. 


\begin{abstract}
Chimeric antigen receptor (CAR) T cell therapy relies on the activity of a large pool of tumortargeting cytotoxic effectors. Whether CAR $\mathrm{T}$ cells act autonomously or require interactions with the tumor microenvironment (TME) is unclear. Here, we report an essential crosstalk between CAR $\mathrm{T}$ cell subsets and the TME for tumor control. Using single-cell RNA sequencing, we revealed profound modification of the TME during CAR T cell therapy. IFN- $\gamma$ produced by CAR T cells and subsequent IL-12 production by the host not only enhanced endogenous $\mathrm{T}$ and NK cell activity but were also essential for sustaining CAR $\mathrm{T}$ cell cytotoxicity as revealed by intravital imaging. Compared to $\mathrm{CD} 8^{+} \mathrm{CAR} \mathrm{T}$ cells, $\mathrm{CD} 4^{+} \mathrm{CAR} \mathrm{T}$ cells were more efficient at host immune activation but less capable of direct tumor killing. In sum, CAR T cells are not acting alone in vivo but rely instead on a cytokine-mediated crosstalk with the TME for optimal activity. Invigorating CAR T cell interplay with the host represents an attractive strategy to prevent relapses.
\end{abstract}




\section{Introduction}

Chimeric antigen receptor (CAR) T cells represent a potentially curative strategy for B cell malignancies. In clinical trials, anti-CD19 CAR T cell therapies reached up to $86 \%$ initial remission rates (1). However, less than $50 \%$ of the patients with aggressive lymphoma will have a durable response past 6 months following CAR T cell therapy (1-4). Understanding the precise mode of action underlying CAR T cell therapy is an essential step to develop strategies to prevent relapses and to extend this treatment to solid tumors. The success of anti-CD19 CAR $\mathrm{T}$ cells is believed to rely on the activity of a large numbers of cytotoxic effectors. In most cases, patients are infused with a mixture of $\mathrm{CD} 4^{+}$and $\mathrm{CD} 8^{+} \mathrm{CAR}$ T cells (referred to as CAR4 and CAR8 T cells) $(3,5,6)$. Like CAR8 T cells, CAR4 T cells have also been shown to exert cytotoxic activity in vitro with differences in killing kinetics or efficiency reported in some studies (7-14). In some in vivo models, CAR4 T cells outperformed CAR8 T cells in mediating tumor regression $(7,8,12,14)$ while CAR8 $\mathrm{T}$ cells were potent in other settings $(10,11)$. However, the in vivo killing potential of single CAR4 versus CAR8 T cells and their respective contributions to tumor regression remain to be quantified.

Using in vivo imaging, we have recently shown that two-thirds of tumor lysis events were directly performed by CAR T cells (15). This highlights that CAR T cell cytotoxicity is a major player driving tumor regression but also suggests the existence of additional mechanisms elicited by CAR T cells in the tumor microenvironment (TME). Both the destruction of tumor cells and the ability of CAR T cells to produce cytokines and chemokines have the potential to alter the TME. Yet, little is known about how CAR T cells interact with and modify the TME. In this respect, preclinical models of CAR $\mathrm{T}$ cell therapy that use immunodeficient mouse models cannot fully address this question. Cellular crosstalks between CAR T cells and the host 
may be important to promote endogenous immune responses. In addition, it is unclear whether CAR $\mathrm{T}$ cells maintain their cytotoxic function in a cell-autonomous manner or whether interactions with the TME are critical for their activity. Finally, the respective role of CAR4 and CAR8 T cells in these potential crosstalks is not fully understood.

To decode the crosstalk between CAR $\mathrm{T}$ cell subsets and the TME, we relied on an immunocompetent mouse model of anti-CD19 CAR T cell therapy and used a combination of intravital imaging, flow cytometry and single-cell RNA sequencing. Our results establish the existence of a cellular crosstalk involving the cytokine IFN- $\gamma$ between CAR T cells and the TME that is essential to promote host immune activation, CAR8 T cell cytotoxic activity and tumor regression. Moreover, we establish the differential contributions of CAR4 and CAR8 T cells to tumor lysis and host immune activation. 


\section{Results}

\section{CAR8 T cells mediate higher tumor cell lysis compared to CAR4 T cells in vivo}

With the aim to delineate the distinct functional contributions of CAR4 and CAR8 T cells to anti-CD19 CAR T cell therapy, we used a syngeneic mouse model of Burkitt-like lymphoma as previously described (15-17). We took advantage of this immunocompetent model receiving a mild conditioning regimen of sublethal irradiation to dissect CAR T cell interactions not only with tumor cells but also with the TME. Lymphoma-bearing mice were treated with anti-CD19 CAR T cells generated from purified $\mathrm{CD}^{+}$or $\mathrm{CD}^{+} \mathrm{T}$ cells in order to identify the specific contribution of each subset (Fig. S1A). Prior to transfer, CAR4 and CAR8 T cell displayed high levels of CAR expression, similar patterns of CD62L and CD44 expression and low surface levels of inhibitory receptors PD-1, Tim-3 and TIGIT (Fig. S2A-C). We first sought to characterize CAR T cell accumulation and cytotoxic activity at the tumor site, using intravital imaging of the bone marrow. To track killing events in real-time, we used tumor cells expressing a genetically encoded reporter for apoptosis (Fig. S1B) $(18,19)$. Both CAR4 and CAR8 T cells were capable of infiltrating and surveying the tumor in the bone marrow as early as day 2-3 post CAR T cell transfer (Fig. 1A, Movie S1). A kinetic analysis revealed that while CAR4 and CAR8 T cells were detected at similar frequency in the blood one day after transfer, CAR8 T cells preferentially accumulated over time at the tumor site and other lymphoid organs (Fig. S3). Of note, a larger fraction of CAR8 T cells (as compared to CAR4 T cells) proliferated when cultured in vitro with tumors possibly contributing to the differential accumulation seen in vivo (Fig. S2D). This CAR8 $\mathrm{T}$ cell accumulation was associated with a near-complete elimination of tumor cells in the bone marrow. To examine in more details the cytotoxic activity of CAR4 and CAR8 T cells, we first quantified the presence of apoptotic tumors and CAR T cells in multiple tumor subregions on day 3. Notably, apoptotic tumor cells colocalized with 
CAR8 but not CAR4 T cells (Fig. 1B) suggesting that CAR8 T cells were more prone to directly mediate tumor cell lysis. When analyzing tumor areas with similar CAR T cell densities (green values between 2 and 6 in Fig. 1B), CAR8 T cells were associated with increased tumor apoptosis compared to CAR4 T cells (tumor apoptosis index $4.84 \pm 0.59$ for CAR4 T cell versus $9.57 \pm 1.23$ for CAR8 T cells; $\mathrm{p}=0.0006)$. In theory, CAR T cells could induce tumor killing in a contact-dependent manner (direct killing) or more indirectly, for example through cytokine release or by acting on other cells (indirect killing). To further characterize CAR4 and CAR8 $\mathrm{T}$ cell cytotoxicity, we classified all tumor apoptotic events detected by real-time intravital imaging (from a total of 108 hours of imaging) based on whether dying tumors were directly contacted by a CAR T cell (referred to as direct apoptotic events) or not (referred to as indirect apoptotic events). Most tumor apoptotic events (72\%) observed in CAR8 T cell-treated mice appeared to be mediated directly by a cellular contact. By contrast, $>80 \%$ of apoptotic events observed in CAR4 T cell-treated mice did not involve a direct interaction (Fig. 1C-D, Movie S2-5). Indirect apoptotic events nevertheless required the presence of CAR T cells and were very rarely observed in untreated recipients (Fig. 1A) (15). More tumor cell apoptosis and a reduced tumor burden were observed in the presence of CAR8 compared to CAR4 T cells as quantified by ex vivo flow cytometry on day 3 (Fig. 1E-F). Of note, endogenous B cells were also more efficiently eliminated by CAR8 T cells as compared to CAR4 T cells (Fig. S4). CAR8 $\mathrm{T}$ cells were also more efficient at killing tumor targets as compared to CAR4 T cells in an in vitro cytotoxic assay, requiring less time and lower E:T ratios (Fig. S5). Consistently, prior to transfer, CAR8 T cells exhibit a higher intracellular granzyme B content and degranulate more upon coculture with tumor cells as compared to CAR4 T cells (Fig. S2E-F). Thus, CAR8 T cells exhibited a higher capacity to eliminate target cells via direct contact as compared to CAR4 $\mathrm{T}$ cells. Of note, CAR4 $\mathrm{T}$ cells could also in theory eliminate tumor cells by releasing cytokines such as IFN- $\gamma$ and TNF- $\alpha$. Yet sensitivity to cell death by these cytokines varies 
extensively between distinct tumors (20) and was not detectable with our MYC-driven B cell lymphoma (Fig. S6). Thus, tumor resistance to cytokine-induced cell death combined with the low CAR4 $\mathrm{T}$ cell killing rate and accumulation in bone marrow most likely contribute to the poor CAR4 T cell anti-tumor activity observed when these cells are used alone. By contrast, the specific accumulation of CAR8 T cells with high killing capacity (Fig. 1G) most likely accounts for the initial tumor regression (Fig. 1A and F) and the significantly prolonged survival observed upon CAR8 T cell therapy in our model (Fig. 1H).

\section{CAR T cells reshape the tumor microenvironment and promote immune activation}

Our results highlighted the importance of CAR8 T cell cytotoxicity. However, whether CAR T cell cytotoxic activity is a fully cell-autonomous process or is supported by interactions with the TME remains unclear. It is also unclear whether the endogenous immune system is regulated by the presence of CAR T cells. To address these questions, we undertook a detailed characterization of the TME in response to CAR4 or CAR8 T cell treatments. First, we performed single-cell RNA sequencing of the TME in recipients that were either left untreated or treated with CAR4 or CAR8 $\mathrm{T}$ cells (on day 3 post-treatment). We identified clusters corresponding to tumor cells, CAR T cells and most host immune cell subsets (Fig. 2A, Fig. S7). CAR8 T cells strongly reduced the presence of B cells and tumors cells, in line with their strong killing activity (Fig. 1E-F). CAR4 T cells only partially reduced endogenous B cells but had little effect on tumor cells, consistent with our imaging and flow cytometry data (Fig. 1A and 1F, Fig. S4). Interestingly, an increased representation of T cells/NKT cells and NK cells was apparent in CAR4 and CAR8 T cell treated compared to untreated conditions (Fig. 2A). Strikingly, cytotoxic genes (Gzma, Gzmb, Prfl) were among the most upregulated genes by CAR4 or CAR8 treatment in endogenous effectors (including T/NKT cells and NK cells) (Fig. 2B-C). Ifng expressing cells were increased upon CAR T cell treatment (Fig. 2C). Together, 
these results strongly suggest that the transfer of CAR4 or CAR8 T cells promoted both the recruitment and the cytotoxic phenotype of host immune effectors. We also observed the upregulation of genes involved in antigen presentation in tumor B cells and some myeloid subsets (plasmacytoid dendritic cells (pDC) and monocytes/macrophages) upon CAR4 and/or CAR8 treatment (Fig. 2D). In sum, our single-cell transcriptomic analysis supported the idea that both CAR4 and CAR8 T cells substantially modify the TME, by boosting the number and the activity of cytotoxic effectors and by increasing the expression of genes related to antigenpresentation at the tumor site.

To further validate and refine these findings, we analyzed the cellular composition of tumorinfiltrated bone marrow cells in response to CAR T cell treatment by flow cytometry (Fig. S8A). CAR4 and CAR8 $\mathrm{T}$ cell therapies led to the accumulation of NK1.1 ${ }^{+}$cells and endogenous $\mathrm{CD}^{+} \mathrm{T}$ cells (Fig. 3A, Fig. S8B). Both CAR4 and CAR8 T cell subsets also increased the frequency of endogenous $\mathrm{CD} 4^{+} \mathrm{T}$ cells, dendritic cells and monocytes although these changes were more pronounced and only reached statistical significance for CAR4 T cell treatment (Fig. 3A). We found that CAR4 $\mathrm{T}$ cells (and to a lesser extent CAR8 $\mathrm{T}$ cells) also triggered a strong recruitment of NK cells, NKT cells, $\mathrm{CD}^{+}{ }^{\mathrm{T}}$ cells, dendritic cells and monocytes in a distinct tumor model using pro-B leukemia cells (Fig. S9), suggesting that this may represent a general feature of CAR T cell therapy. Both CAR T cell subsets led to increased intracellular granzyme B levels in NK1.1 $1^{+}$cells $($Fig. 3B), however CAR4 T cells were more prone to increase granzyme B expression in endogenous $\mathrm{CD}^{+} \mathrm{T}$ cells (Fig. 3C). CAR T cells also led to increased surface expression of major histocompatibility complex (MHC) class II on monocytes (Fig. 3D). To test whether CAR T cells could specifically enhance endogenous tumor-specific T cell responses, we used ovalbumin (OVA)-expressing lymphoma B cells and quantified the frequency of OVA-specific $\mathrm{CD}^{+} \mathrm{T}$ cells by MHC-peptide tetramer staining in tumor-bearing mice treated with CAR4 T cells, CAR8 T cells or left untreated (Fig. S8A) . 
OVA-specific T cell responses were significantly increased in the blood and in the bone marrow upon CAR4 T cell treatment (Fig. 3E). A similar trend was observed with CAR8 T cells but did not reach statistical significance (Fig. 3E). In sum, both CAR4 and CAR8 T cell treatments induced a broad activation of the host immune system at the tumor site with both overlapping and unique contributions for each CAR T cell subset. Despite their lower accumulation at the tumor site, CAR4 T cells were overall more efficient at mobilizing the host immune system. The superior capacity of CAR4 T cells to boost the host immune system could possibly contribute to the improved anti-tumor efficacy observed when CAR4 T cells were added to CAR8 T cells (Fig. S10).

\section{CAR T cell-derived IFN- $\gamma$ is essential for host immune cell recruitment and activation}

When considering all cells present in the TME, our transcriptomic analysis revealed a strong interferon (IFN) signature induced by CAR4 or CAR8 T cells (Fig. 4A) including the upregulation of Ifitm 1, Ccl5, B2m, H2-D1, H2-K1 (Fig. 4A). As illustrated in Fig. 4B, these changes were not restricted to a single cell population but were instead shared between the various immune cell subsets (conventional type 1 dendritic cells (cDC1), pDC, monocytes/macrophages, NK cells, T/NKT cells, neutrophils) and tumor cells, suggesting widespread cytokine signaling. Both type I and type II IFN could potentially contribute to these effects. To test whether CAR T cell-derived IFN- $\gamma$ played a dominant role in these broad changes on the TME, we compared the effects mediated by wild-type (WT) or IFN- $\gamma$-deficient CAR4 or CAR8 T cells using flow cytometry. Notably, a detectable population of WT CAR4 and CAR8 $\mathrm{T}$ cells isolated from the tumor produced IFN- $\gamma$ even in the absence of restimulation (Fig. S11). We confirmed that MHC class I molecules were upregulated at the protein level within the TME by either CAR4 or CAR8 T cells and found that CAR T cellderived IFN- $\gamma$ was essential for this effect using CAR T cells derived from IFN- $\gamma^{-/-}$mice (Fig. 
4C-D). Taken together, these results indicate that IFN- $\gamma$ produced by either CAR4 or CAR8 T cells impacts most cells present in the TME, consistent with the recently described long-range effect of IFN- $\gamma(20,21)$.

Based on these findings, we also investigated whether IFN- $\gamma$ was implicated in CAR T cellmediated activation of the host immune system. The accumulation of NK cells and NKT cells at the tumor site was largely dependent on IFN- $\gamma$ derived from CAR4 or CAR8 T cells (Fig. 5A). The recruitment of dendritic cells and monocytes was also significantly regulated by CAR4 T cell-derived IFN- $\gamma$ (Fig. 5A, Fig. S8C). In addition, CAR T cell-derived IFN- $\gamma$ was also essential for optimal activation of cytotoxic effectors (NK cells, NKT cells and CD8 ${ }^{+} \mathrm{T}$ cells), as measured by intracellular granzyme B content (Fig. 5B-D). IFN- $\gamma$ produced by CAR T cells also controlled MHC class II upregulation at the surface of monocytes (Fig. 5E). Given the broad impact of CAR T cell-derived IFN- $\gamma$ in the TME, we assessed whether it could also affect CAR T cells themselves focusing on the cytotoxic activity of CAR8 T cells. Consistent with this hypothesis, we found that IFN- $\gamma$-deficient CAR8 T cells had sharply decreased intracellular granzyme B content in vivo (Fig. 5F). In sum, these results establish that CAR T cell-derived IFN- $\gamma$ promotes anti-tumoral immune responses by at least two mechanisms: i) by activating host immune responses at the tumor site and ii) by enforcing CAR8 $\mathrm{T}$ cell cytotoxic phenotype.

\section{A cellular crosstalk involving IFN- $\gamma$ in the TME sustains CAR T cell cytotoxicity}

Given the role of IFN- $\gamma$ produced by CAR T cells in promoting the cytotoxic phenotype of host effectors and CAR T cells themselves, we tested its functional contribution to tumor control. We addressed this question in the context of CAR8 T cells since CAR4 T cells were unable to control tumor burden in our model (Fig. 1H). We found that IFN- $\gamma$-deficient CAR8 T cells were inefficient at controlling tumor growth resulting in a significantly decreased survival 
compared to WT CAR8 T cell-treated mice (Fig. 6A). IFN- $\gamma$ could potentially act directly on tumor cells, on CAR T cells as well as on host cells in the TME. To test whether host cell responses to IFN- $\gamma$ is important for CAR8 $\mathrm{T}$ cell anti-tumor activity, we treated tumor-bearing IFN- $\gamma$ R-deficient recipients with WT CAR8 T cells. IFN- $\gamma$-competent CAR8 T cell were unable to control tumor growth when the host was incapable of sensing IFN- $\gamma$ (Fig. 6A). Consistent with these results, we found that elevated granzyme B expression in CAR T cells not only required the production of IFN- $\gamma$ by CAR T cells (Fig. 5G) but also the ability of the host to respond to the cytokine (Fig. 6B). Together, these results establish that a crosstalk involving CAR T cell-derived IFN- $\gamma$ and the TME is essential to sustain CAR T cell cytotoxic phenotype in situ.

We also tested whether the production of IFN- $\gamma$ by host cells contributes to CAR T cell activity. First, we observed that the concentration of IFN- $\gamma$ in the serum increased upon transfer of WT but not IFN- $\gamma^{-/-}$CAR8 T cells, suggesting that CAR T cells are the major source of IFN- $\gamma$. Second, we treated IFN- $\gamma$-deficient tumor-bearing mice with WT CAR8 T cells. Despite the absence of endogenous IFN- $\gamma$, the IFN signature, the CAR T cell cytotoxic phenotype and the tumor control were comparable to that observed in IFN- $\gamma$-competent hosts, indicating the CAR T cell-derived IFN- $\gamma$ is in fact sufficient to promote anti-tumor activity (Fig. S12).

To relate IFN- $\gamma$-dependent changes in CAR T cell cytotoxic phenotype to their killing activity in vivo, we analyzed killing dynamics of WT or IFN- $\gamma$-deficient CAR8 T cells by intravital imaging (Movie S6-7). We found that IFN- $\gamma^{-/-}$CAR8 T cells accumulated to a larger extent at the tumor site as compared to their WT counterparts, possibly due to their resistance to IFN- $\gamma$ induced clonal deletion (22). However, despite being more numerous at the tumor site (Fig. 6C-D), IFN- $\gamma$-deficient CAR8 T cells induced significantly less tumor apoptosis (Fig. 6C and E-F). When quantifying direct (contact-dependent) CAR T cell killing events, we found a two- 
fold reduction in the rate of tumor killing in mice treated with IFN- $\gamma^{-/-}$compared to WT CAR8 T cells (Fig. 6G). Indirect killing was less affected, possibly due to IFN- $\gamma$ independent host cytotoxicity. When normalized to the density of CAR T cells present in the tumor, the killing activity on a per CAR T cell basis was reduced by 4.4 -fold in the absence of IFN- $\gamma$ (Fig. 6H). Of note, this defect was acquired in vivo as WT and IFN- $\gamma$-deficient CAR T cells exhibited identical in vitro killing activity prior to transfer (Fig. S13). Taken together, these results demonstrate that IFN- $\gamma$ produced by CAR T cells acts on the TME to further potentiate the killing rate of CAR T cells and promotes tumor regression.

\section{IL-12 contributes to the crosstalk between CAR T cells and the TME}

We next asked which factors produced by the TME may sustain CAR T cell cytotoxicity. Given the importance of IFN- $\gamma$ in our model, one potential candidate is IL-12 since IFN- $\gamma$ and IL-12 mutually induce their production and since IL-12 is well-known to promote cytotoxic responses $\underline{\text { of conventional } \mathrm{CD} 8^{+} \mathrm{T} \text { cells }(23-29)} . \mathrm{IL}-12$ mRNA was detected in the TME at low levels and was primarily expressed by cDC1 (Fig. 7A), a finding consistent with a recent study of the $\underline{T M E}$ in a solid tumor treated by checkpoint blockade (25). At the protein level, we found that CAR T cells increased intratumoral IL-12p70, albeit modestly, but in manner that was dependent on the ability of CAR T cells to produce IFN- $\gamma$ (Fig. 7B). Reciprocally, intratumoral IFN- $\gamma$ levels were reduced in IL12p35 $5^{-/}$hosts during CAR T cell therapy, suggesting a positive feedback loop between CAR T cell-derived IFN- $\gamma$ and host IL-12 (Fig. 7B). As an independent approach to assess the link between IFN- $\gamma$ and IL-12 in CAR T cell therapy, we cocultured B cell tumors, CAR T cells and a DC cell line previously shown to be competent for IL-12 production (30). As shown in Fig. S14, the presence of CAR T cells increased intracellular IL12 levels in DCs in a manner that was partly dependent on CAR T cell-derived IFN- $\gamma$. To test whether IL-12 could restore the cytotoxic phenotype of IFN- $\gamma$-deficient CAR8 T cells, mice 
treated by IFN- $\gamma^{-/-}$CAR8 T cells were supplemented with recombinant IL-12 for 3 days. IL-12 supplementation was sufficient to rescue the defect in granzyme B content observed in IFN- $\gamma$ deficient CAR8 T cells $\underline{\text { (Fig. 7C). }}$. To test whether IL-12 is also required to sustain CAR8 T cell cytotoxic phenotype, we analyzed the cytotoxic phenotype of WT CAR8 T cells injected in tumor-bearing $I l 12 p 35^{-/-}$hosts. We found that in the absence of host IL-12 production, CAR8 $\mathrm{T}$ cells displayed reduced granzyme B intracellular content (Fig. 7D). In addition, the lack of host IL-12 also strongly reduced the boost of endogenous cytotoxic effectors $\left(\mathrm{CD} 8^{+} \mathrm{T}\right.$ cells, NK cells, NKT cells) mediated by CAR T cell therapy (Fig. 7E). Altogether our data suggest that the crosstalk between CAR T cells and the TME relies on the cytokines IFN- $\gamma$ and IL-12 and is essential for optimal cytotoxic activity (Fig. S15). 


\section{Discussion}

Here, we established that the anti-tumor activity mediated by CAR T cells largely relies on cellular crosstalk within the TME. Mechanistically, IFN- $\gamma$ produced by CAR T cells and sensed by the host was essential to boost the cytotoxic potential of CAR T cells and of host NK and T cells. In this context, CAR4 and CAR8 T cells exhibited complementary functions being more efficient at immune activation and tumor killing, respectively.

Patients treated by CAR T cells are typically infused with a mixture of CAR4 and CAR8 T cells $(3,5,6)$. Yet, the exact contribution of each CAR T cell subset in vivo is not fully understood. Both subsets can exhibit cytotoxic activity in vitro and transfer of CAR4 T cells in some preclinical models can lead to tumor eradication (7-14). Using intravital imaging, we established that CAR8 T cells played a dominant role in contact-dependent cytotoxicity. This was due to a much higher killing rate on a per cell basis as well as to a more pronounced accumulation at the tumor site as compared to CAR4 $\mathrm{T}$ cells. It is interesting to note, that the relative efficacy of CAR4 and CAR8 T cells varies in different preclinical settings $(7,8,10$ 12, 14). In particular, in a distinct leukemia model, Yang et al. observed efficient anti-tumor activity mediated by CAR4 $\mathrm{T}$ cells (14). CAR4 T cells help host effectors and it is possible that tumor infiltration by host cells varies between models. Additionally, CAR4 T cells may possibly exert anti-tumor activity through cytokine-induced tumor cell death (involving for example IFN- $\gamma$ and TNF- $\alpha$ ), yet there exist extensive differences in individual tumor sensitivity to cytokines (20). The fact that the MYC-driven B cell lymphoma used in this study is poorly sensitive to cell death mediated by IFN- $\gamma$ and TNF- $\alpha$ may also contribute to the lack of efficacy of CAR4 T cells when used alone in this model. The behavior of CAR4 T cells and tumor cells characterized in our model may serve as a reference point to compare the role CAR4 T cells in different preclinical models. 
Using single-cell transcriptomic and flow cytometry analyses, we also established that CAR4 and CAR8 T cells profoundly reshape the TME, in particular by boosting cytotoxic effectors. This important feature of CAR T cell therapy may have been overlooked due to the prominence of immunodeficient mouse models (including patient-derived xenograft) that cannot fully recapitulate CAR T cell crosstalk with the host. By and large, CAR4 T cells were more efficient than CAR8 T cells at host immune activation. When used alone CAR4 T cells were nevertheless unable to control tumor burden suggesting that activated host effectors may not be sufficiently numerous at the tumor site to promote tumor regression. Overall, CAR4 and CAR8 T cells appeared to exhibit complementary functions, being specialized in immune activation and tumor killing respectively. Such a division of labor supports a rationale for the careful control of the CAR4:CAR8 T cell ratio in the infused products $(31-33)$.

We found that the ability of CAR T cells to produce IFN- $\gamma$ and the host response to the cytokine were essential for tumor regression. We and others have reported the ability of IFN- $\gamma$ to diffuse and act over long distances in the TME $(20,21)$. Consistently, during CAR T cell therapy, IFN$\gamma$ was sensed by most immune cells in the TME, as reflected by widespread MHC class I upregulation.

Our results with anti-CD19 CAR T cells extend previous studies that showed impaired antitumor responses by conventional (34-36) or engineered T cells (37-39) in the absence of host IFN- $\gamma \mathrm{R}$ expression. Thus, in addition to the direct effects mediated by IFN- $\gamma$ on tumor cells (40, 41), distinct mechanisms have been proposed to explain the importance of host IFN- $\gamma$ sensing, including modulation of neoangiogenesis $(42,43)$, immune recruitment and activation $(37-$ 39), tumor immunogenicity (35) and destruction of the tumor stroma (36). In the context of CAR T cell therapy, we uncovered a new mechanism in that IFN- $\gamma$ sensing together with IL-12 
production by host cells is essential to sustain CAR $\mathrm{T}$ cell cytotoxicity in situ. Indeed, quantification of killing dynamics by intravital imaging revealed that in the absence of IFN- $\gamma$, CAR8 $\mathrm{T}$ cells exhibited an average of 4 to 5 -fold decrease in their tumor killing rate. It is interesting to note that a cellular crosstalk involving IFN- $\gamma$ and IL-12 was also important to boost $\mathrm{T}$ cell responses during anti-PD-1 therapy (25). These findings made in two very different contexts raise the possibility that robust IFN- $\gamma$ production represents a universal requirement to sustain anti-tumor cytotoxic activity.

Previous studies using chimeric NKG2D-expressing T cells have pointed at interactions with host immunity $(37,38,44,45)$. In addition, CAR T cells engineered to overexpress cytokines such as IL-12 (10, 46-49), IL-15 (50), IL-18 (51), IL-7 (52) or chemokine such as CCL19 (52) can confer improved anti-tumor activity, in part by boosting host immunity. Upon successful therapy, CAR T cells can also protect against subsequent challenges with antigen-negative tumors $(46,52-54)$. In our syngeneic model, we found that conventional anti-CD19 CAR T cells promote the accumulation and the activation of host T cells and NK cells with again a key role for IFN- $\gamma$. Future studies should help dissect the respective contributions of the various host effectors and cytokines to 'indirect' killing events. We have shown that CAR T cells can promote tumor-specific $\mathrm{T}$ cell responses. The fact that CAR $\mathrm{T}$ cells also boost antigenpresentation capacity at the tumor site likely favors epitope spreading. Relapse in particular due to emergence of antigen-negative tumor represents a substantial hurdle for CAR T cell therapy $(3,55-57)$ suggesting that curative strategies should aim at boosting host immunity to reach durable response and avoid emergence of antigen-escape variants. In this respect, reduction of immunosuppressive pretreatments (including conditioning) may help patients benefit from CAR T cell mediated-boost of residual host immunity. Exploiting the molecular and cellular 
players identified in CAR T cell interactions with the TME therefore represents an attractive opportunity for combination therapies aimed at preventing relapses.

Potential limitations of our study include the fact the exact contribution of host effectors ( $\mathrm{T}$ cells and NK cells) to tumor regression remains to be precisely determined. Additionally, our $\underline{\text { results do not exclude the possibly that additional cytokines contribute to the crosstalk between }}$ CAR T cells and the TME.

In sum, our results provide new insights into how CAR4 and CAR8 T cells and the host immune system act together to generate optimal anti-tumor activity and establish that IFN- $\gamma$ production is integral to successful CAR $\mathrm{T}$ cell activity. A detailed understanding of CAR $\mathrm{T}$ cell interactions with the TME represents an important step toward the rational design of improved CAR T cell therapies. 


\section{Materials and methods}

\section{$\underline{\text { Study design }}$}

$\underline{\text { The aim of this study was to investigate whether CAR T cells act autonomously or require }}$ interactions with the TME to promote effective tumor regression. To this end, we relied on an $\underline{\text { immunocompetent mouse model of anti-CD19 CAR T cell therapy and used a combination of }}$ flow cytometry, two-photon intravital imaging in the bone marrow and single-cell RNA sequencing. We established the existence of a cellular crosstalk involving CAR T cell-derived $\underline{\text { IFN- } \gamma \text { and host IL-12 for optimal anti-tumor activity. We also delineated the functional }}$ $\underline{\text { contributions of CAR4 and CAR8 T cells, being specialized in immune activation and tumor }}$ killing respectively. The number of mice per experimental group and the number of repetitions of each experiment is indicated in individual figure legends.

\section{Mice and cell lines}

6 to 8-week-old C57BL/6J male mice were obtained from Envigo. UBC-GFP, Ifng ${ }^{-/}$, $I l 12 p 35^{-/-}$and IfngRI $1^{-/}$mice were bred and crossed in our animal facility under specific pathogen-free conditions. All experiments were approved by Institut Pasteur's Safety Committee in accordance with French and European guidelines (CETEA 2017-0038). A lymphoma B cell line was isolated from tumor-bearing male $\mathrm{E} \mu$-myc mice, a transgenic mouse developing spontaneous Burkitt-like lymphomas (17). Immortalized pro-B cells were generated by infecting bone marrow cells with a retrovirus encoding viral-Abelson kinase (v-abl) (58). When indicated, these cell lines were retrovirally transduced to express a fluorescence resonance energy transfer (FRET)-based reporter for caspase-3 activity $(18,19)$ and ovalbumin. Mice were examined every day and sacrificed in case of prostration, tousled hair, weakness or nodal tumor mass $>1 \mathrm{~cm}$. Cells were cultured in RPMI medium 1640- 
GlutaMAX $^{\mathrm{TM}}$ supplemented with $10 \%$ heat-inactivated fetal bovine serum, 50 U.mL ${ }^{1}$ penicillin, $50 \mu \mathrm{g} \cdot \mathrm{mL}^{-1}$ streptomycin, $1 \mathrm{mM}$ sodium pyruvate, $10 \mathrm{mM}$ HEPES and $50 \mu \mathrm{M} 2-$ mercaptoethanol, and maintained at $37^{\circ} \mathrm{C}$ and $5 \% \mathrm{CO}_{2}$. Mutu DCs originate from the spleen of CD11c:SV40LgT-transgenic mice (30) and were cultured in Iscove's Modified Dulbecco's Medium (IMDM) + GlutaMAX-I supplemented with 10\% heat-inactivated fetal bovine serum, $\underline{50 \mathrm{U} \cdot \mathrm{mL}^{-1} \text { penicillin, } 50 \mu \mathrm{g} \cdot \mathrm{mL}^{-1} \text { streptomycin, } 1 \mathrm{mM} \text { sodium pyruvate, } 10 \mathrm{mM} \text { HEPES and } 50}$

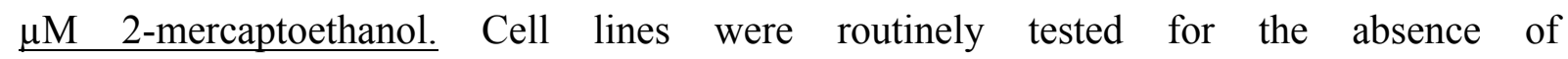
Mycoplasma contamination (Venor-GeM Advance mycoplasma detection kit, Minerva Biolabs).

\section{CAR T cell generation and adoptive transfer}

The tCD34.2A.amCD19.CD28IEV $\zeta$ retroviral vector encoding anti-CD19 CAR has been described previously (59). Briefly, the CAR construct is composed of the murine anti-murine CD19 single-chain fragment variable domain derived from the 1D3 rat hybridoma, the transmembrane and intracellular domains of CD28, and the CD3z intracellular domain. The retroviral vector also encodes a truncated human CD34 molecule used for identification and purification of CAR T cells. Polyclonal $\mathrm{CD} 4^{+}$and $\mathrm{CD} 8^{+} \mathrm{T}$ cells were purified from lymph nodes and spleens of male WT, UBC-GFP, Ifng ${ }^{-/}$mice using CD4-negative and CD8-negative selection kits (Miltenyi Biotec). T cells were activated in plates coated with $2.5 \mu \mathrm{g} \cdot \mathrm{ml}^{-1}$ antiCD3 mAb (clone 17.A2; BioLegend) in the presence of $2.5 \mu \mathrm{g} . \mathrm{ml}^{-1}$ soluble antiCD28 mAb (clone 37.51; BioLegend) and 10 ng.ml ${ }^{-1}$ murine IL-12 (I8523; Sigma-Aldrich) (60). Two rounds of spin-infection were performed at 24 and 48 hours after T cell activation using retroviral particles supplemented with $8 \mu \mathrm{g} \cdot \mathrm{ml}^{-1}$ polybrene (Merck). T cells were cultured for 4 additional days in the presence of $10 \mathrm{ng} \cdot \mathrm{ml}^{-1} \mathrm{hIL}-2$ (202-IL; R\&D Systems). For proper in vitro activation, IFN- $\gamma$-deficient T cells and their WT counterparts were supplemented with 100 
ng.ml $l^{-1}$ of IFN- $\gamma$ (Peprotech). If necessary (transduction efficacy $<80 \%$ ), purification of transduced cells was performed using hCD34 positive selection kit (Miltenyi Biotec). B cell lymphoma was established by injecting $0.5 \times 10^{6}$ E $\mu$-myc cells or $0.5 \times 10^{6}$ transformed pro-B cells in mice following a sublethal irradiation ( $4 \mathrm{~Gy}$ ), used as a conditioning regimen for CAR $\mathrm{T}$ cell engraftment (61). Tumor develops primarily in the bone marrow and became detectable in the blood by day 6-7 at which time $10-20 \times 10^{6}$ CAR T cells were injected intravenously (i.v.). When indicated, mice were not irradiated but received $50 \mu \mathrm{g}$ i.v. of anti-CD20 monoclonal antibody (5D2, mIgG2a; Genentech) as a conditioning regimen (15) 2 days before CAR T cell transfer. For in vivo cytokine supplementation studies, recombinant IL-12 (1 $\mu \mathrm{g}$ in $100 \mu \mathrm{L}$ PBS) (recombinant mouse IL12-p70; Peprotech) was delivered daily intraperitoneally for 3 days starting at CAR T cell transfer.

\section{Flow cytometry and antibodies}

For ex vivo analysis, bone marrow cells were isolated by flushing femurs and tibias from tumorbearing mice and subsequent filtering through $70 \mu \mathrm{m}$ cell strainers. Single-cell suspensions from spleen and lymph nodes were prepared by filtering the cells through $70 \mu \mathrm{m}$ cell strainers. Blood was collected by cardiac puncture after mouse sacrifice and red blood cells were removed using red blood cell lysis buffer (eBiosciences). Bone marrow and blood cell suspensions were Fc-blocked using anti-CD16/32 mAbs (clone 93; BioLegend). Stainings were performed with the followings mAbs: hCD34-PE (clone 561; BioLegend) or Alexa Fluor 647 (clone 561; BioLegend) or BUV395 (clone 581; BD Biosciences), CD3e-FITC (clone 1452C11; BioLegend), CD19-PE/Cy7 (clone 6D5; BioLegend) or APC-fire750 (clone 6D5; BioLegend) or BV421 (clone 6D5; BioLegend), CD8a-BUV395 (clone 53-6.7; BD Biosciences), CD4-BV786 (clone RM4-5; BD Biosciences) or BV421 (clone GK1.5; BioLegend), NK1.1-PE/Cy7 (clone PK136; BioLegend) or BV421 (clone PK136; BioLegend), 
CD45.2-BUV737 (clone 104; BD Biosciences), CD11b-PE/Cy7 (clone M1/70; BioLegend) or BUV395 (clone M1/70; BD Biosciences), CD11c-APC (clone N418; BioLegend), Ly6CBV605 (clone HK1.4; BioLegend), Ly6G-BUV395 (clone 1A8; BD Biosciences), I-A/I-EAPC-fire750 (clone M5/114.15.2; BioLegend), H-2Db-APC (clone KH95; BioLegend), H2Kb-PE/Cy7 (clone AF6-88.5; BioLegend), c-kit-BV421 (clone 2B8; BioLegend), TCR $\beta$ chain-BV421 (clone H57-597; BioLegend), CD34-BV421 (clone SA376A4; BioLegend), TER-119-BV421 (clone TER-119; BioLegend), CD44-Alexa488 or BV605 (clone IM7; BioLegend), CD62L-BV421 (clone MEL-14; BioLegend), TIGIT-PE (clone GIGD7; eBiosciences), PD-1-PE/Cy7 (clone J43; BioLegend), Tim-3-APC (clone RMT3-23; BioLegend), and CD107a-Alexa647 (clone 1D4B; BioLegend). H-2Kb-OVA (SIINFEKL) monomers were produced as previously described $(62,63)$ and fluorescent tetramers were prepared using PE-conjugated UltraAvidin (Leinco Technologies). Intracellular stainings were performed using the Cytofix/Cytoperm kit (BD Biosciences) according to the manufacturer's guidelines, Alexa647-conjugated anti-Granzyme B mAb (clone GB11; BioLegend), BUV737conjugated anti-IFN- $\gamma$ mAb (clone XMG1.2; BD Biosciences) and PerCP-Cy5.5-conjugated anti-IL-12/IL-23p40 mAb (clone C17.8; eBiosciences). IFN- $\gamma$ and IL-12 expression was assessed in the presence of $1 \mu \mathrm{g} \cdot \mathrm{ml}^{-1}$ of Brefeldin A (BD Biosciences). CD107a surface expression on CAR T cells was assessed using antibody directly in the coculture. For in vitro CAR $\mathrm{T}$ cell proliferation, CAR $\mathrm{T}$ cells were loaded with CellTrace Far Red dye (Life Technologies) according to the manufacturer's guidelines. Analyses were performed using a Cytoflex LX (Beckman Coulter) flow cytometer and analyzed with FlowJo v10.6.2 (BD). Tumor apoptosis was quantified using a FRET-based reporter for caspase-3 activity, and FRET loss was defined as a derived parameter using the ratio of CFP to FRET fluorescence. FRET loss was measured on cells fixed with $2 \%$ paraformaldehyde solution (Sigma) immediately after ex vivo isolation. 


\section{Cytotoxicity assays}

For killing experiments, effectors and target cells were mixed at 1:1 to 20:1 effector:target ratio in 96-well plates and spun $1 \mathrm{sec}$ at $1200 \mathrm{rpm}$. After 2 to 24 hours, FRET loss in tumor cells and remaining target cells were determined by flow cytometry. The percentage of specific killing was calculated as $100 \times(1-$ target cells in well/target cells in well without effectors).

\section{Intravital two-photon imaging of the bone marrow}

Bone marrow intravital imaging was performed 2 to 6 days after CAR T cell transfer, as described (15). Briefly, mice were anesthetized with a mixture of xylazine (Rompun ${ }^{\circledR}, 10$ mg. $\mathrm{kg}^{-1}$ ) and ketamine (Imalgene $\left.{ }^{\circledR}, 100 \mathrm{mg} \cdot \mathrm{kg}^{-1}\right)$. The scalp was incised at the midline and then exposed. The jaw was fixed on the surface of a steel plate. A round coverslip was fixed above the frontoparietal suture after PBS deposition using a cyanoacrylate-based glue. During imaging, mice were supplied with oxygen and temperature was maintained at $37^{\circ} \mathrm{C}$ using a heated-pad. Two-photon imaging was performed with an upright microscope FVMPE-RS (OLYMPUS) and a 25x/1.05 numerical aperture, water-dipping objective (OLYMPUS) combined with an objective heater. Excitation was provided by an Insight DeepSee dual laser (Spectra-Physics) tuned at $880 \mathrm{~nm}$. The following filters were used for fluorescence detection: CFP (483/32), GFP (520/35 or 512/25), YFP (542/27), background (593/35). To create timelapse sequences, we typically scanned a 30 to $40 \mu \mathrm{m}$-thick volume of tissue at $5 \mu \mathrm{m} \mathrm{Z}$-steps and $60 \mathrm{sec}$ intervals. For static mosaics, $150 \mu \mathrm{m}$-thick volume of tissues at $5 \mu \mathrm{m} \mathrm{Z}$-steps were typically imaged.

\section{Image analysis}


Videos were processed and analyzed using Fiji software (ImageJ 2.0.0). Figures and videos based on two-photon microscopy are shown as $2 \mathrm{D}$ maximum intensity projections of $3 \mathrm{D}$ data. Tumor apoptotic events were manually quantified and scored as direct killing when a CAR T cell engaged the tumor cell before the detection of FRET loss. Indirect events corresponded to tumor cells undergoing FRET loss without any detectable interactions with a CAR T cell during the imaging period. To perform an unbiased analysis of the spatial localization of apoptotic tumors and CAR T cells, we developed an in-house Fiji script that computes a correlation score. Briefly, for each bone marrow mosaic of 2000x2000 $\mu \mathrm{m}$, both CFP and GFP channels are first binarized using the Yen threshold. Then for each region of interest (ROI) of 100x100 $\mu \mathrm{m}$ (spaced $50 \mu \mathrm{m}$ apart), the mean CFP and GFP values are calculated and considered as a good proxy for apoptotic tumor and CAR T cell presence. For determining tumor cell area (CFP + YFP), apoptotic tumor cell area (CFP) and CAR T cell area (GFP) from in vivo images, each channel was binarized and subjected to surface area calculation.

\section{Single-cell RNA sequencing and analysis}

B cell lymphoma was established by i.v. injection of $0.5 \times 10^{6}$ E $\mu$-myc-DEVD cells in C57BL/6J mice after sublethal irradiation (4 Gy). Six days later, mice were injected i.v. with $20 \times 10^{6}$ CAR4 or CAR8 T cells or left untreated. Bone marrow cells from one tibia and one femur per mouse were harvested 3 days after initiation of therapy. Erythroblast cells were magnetically removed using anti-Ter-119 biotin-labeled monoclonal antibodies and streptavidin-labeled magnetic beads (Mojosort streptavidin nanobeads, BioLegend). Single-cell suspensions were prepared by filtering the cells through $70 \mu \mathrm{m}$ cell strainers. Single cells were encapsulated using the $10 \mathrm{x}$ Chromium 3' v2 chemistry kit according to the manufacturer's instructions (10X Genomics). Libraries of cDNA were prepared according to the manufacturer's instructions. Samples were sequenced by Macrogen using HiSeq X ten platform (Illumina). Reads were processed with the 
10x pipeline Cellranger 3.1.0 and the count command. We used the mm10 genome and transcriptome annotations provided by $10 \mathrm{X}$ Genomics. We added two sequences to this assembly. First a consensus sequence of three fluorescent proteins (CFP, YFP and EGFP for identification of FRET-based caspase-3 reporter in tumor cells and GFP-expressing CAR T cells). We also added a segment of the CAR plasmid sequence. For these two additional sequences, we added in the annotation files features on both strands. We used R package Seurat 3.1.1 for analyzing the data (64). From the raw Cellranger output, we selected cells with more than 1,000 unique molecular identifiers (UMIs) and less than $20 \%$ of mitochondrial UMIs (untreated (12,348 cells), CAR4-treatment (9,895 cells), CAR8-treatment (7,798 cells)). We computed 2,000 variable genes and used 50 principal components (PCs) for neighbors finding and clustering. We also used 50 PCs for generating the Uniform Manifold Approximation Projection (UMAP) in this paper. For violin plots, Wilcoxon test was used. For volcano plots, Wilcoxon test and Bonferroni method for $\mathrm{p}$ value correction were used. Singlecell RNA sequencing data are available at the Gene Expression Omnibus (GEO) accession number GSE165797.

\section{Multiplex assay for cytokine quantification}

Three days after CAR T cell transfer, bone marrow cells were isolated by flushing femurs and tibias from tumor-bearing mice, filtered through $70 \mu \mathrm{m}$ cell strainers and washed with cold PBS. Cells were lysed using NP40 Cell Lysis Buffer (Invitrogen) following manufacturer's instructions and stored at $-80^{\circ} \mathrm{C}$ until analysis. Multiplex assay was performed using 26Plex ProcartaPlex Panel (Invitrogen) following manufacturer's instructions. Standards were reconstituted with Universal Assay Buffer diluted at 1:2 in assay diluent. For analyte capture, the plate was incubated overnight at $4^{\circ} \mathrm{C}$ under agitation on an orbital shaker. Analyses were performed using a Bio-Plex 200 system equipped with Bio-Plex Manager software (Bio-Rad). 


\section{Statistical Analysis}

All statistical tests were performed using Prism v.6.0a (GraphPad). Data are expressed as mean

\pm SEM. Unpaired Student's t test, Mann-Whitney U test, one-way analysis of variance (ANOVA) and two-way ANOVA were used as indicated in individual figure legends, using post hoc Tukey and Holm-Sidak test for multiple comparison correction. All statistical tests were two-tailed with a significance level of 0.05 . ns, not significant; ${ }^{*} \mathrm{p}<0.05 ;{ }^{*} \mathrm{p}<0.01$; $* * * \mathrm{p}<0.001$

\section{Supplementary Materials}

Fig S1. Assessing the cytotoxic potential of anti-CD19 CAR4 and CAR8 T cells in vivo using a genetically encoded reporter for apoptosis.

Fig S2. In vitro phenotyping of CAR4 and CAR8 T cells prior to adoptive cell transfer.

Fig S3. Kinetics of CAR T cell accumulation in blood and lymphoid organs.

Fig S4. CAR4 T cells are poorly effective at eliminating endogenous B cells in vivo.

Fig S5. CAR4 T cells are poorly effective at inducing tumor cell killing in vitro.

Fig S6. Tumor sensitivity to cytokine-induced cell death.

Fig S7. Identification of tumor infiltrating immune cells by single-cell RNA sequencing.

Fig S8. CAR T cells promote host immune cell recruitment at the tumor site.

Fig S9. CAR T cell therapy induces a broad mobilization of host immunity in a model of proB leukemia cells.

Fig S10. Combining CAR4 and CAR8 T cells improves anti-tumor activity.

Fig S11. WT CAR T cells produce IFN- $\gamma$ at the tumor site in vivo.

Fig S12. CAR T cell-derived IFN- $\gamma$ is sufficient to promote anti-tumor activity. 
Fig S13. WT and IFN- $\gamma$-deficient CAR8 T cells exhibit similar killing activities prior to in vivo transfer.

Fig S14. CAR T cell-derived IFN- $\gamma$ promotes IL-12 expression by DCs in vitro.

Fig S15. CAR T cell-mediated anti-tumor activity relies on cellular crosstalks within the tumor microenvironment.

Movie S1. Both CAR4 and CAR8 T cells infiltrate and patrol tumor-invaded bone marrow.

Movie S2. Direct tumor cell killing mediated by a CAR4 T cell.

Movie S3. Direct tumor cell killing mediated by a CAR8 T cell.

Movie S4. Tumor B cell undergoing apoptosis without detectable contact with CAR4 T cells.

Movie S5. Tumor B cell undergoing apoptosis without detectable contact with CAR8 T cells.

Movie S6. WT CAR8 T cells induce efficient tumor cell killing in the bone marrow.

Movie S7. IFN- $\gamma$-deficient CAR8 T cells are poorly cytotoxic at the tumor site.

Table S1. Raw data file; Excel spreadsheet. 


\section{Acknowledgments}

We thank M. Lecuit for providing IL-12p35-deficient mice and members of the Bousso laboratory for critical review of the manuscript. We acknowledge the mouse facility and CB UTechS at Institut Pasteur for support in conducting this study with the specific contribution of Valentina Libri.

Funding: The work was supported by Institut Pasteur, Inserm and an Advanced grant (ENLIGHTEN) from the European Research Council (P.B). M. Cazaux received financial support from ITMO Cancer 'Alliance Nationale pour les Sciences de la Vie et de la Santé' within the framework of the Cancer Plan.

Author contributions: M.B., M.C., R.T., B.C., F.L., C.G. and Z.G. conducted the experiments. M.B., M.C. and P.B. designed the experiments. Y.LM. performed the sequencing analysis. M.B., M.C. and P.B. analyzed the data and wrote the manuscript.

Competing interests: The authors declare no competing interests.

Data and materials availability: $\underline{\text { Single-cell RNA sequencing data are available at the Gene }}$ Expression Omnibus (GEO) accession number GSE165797. All other data needed to evaluate the conclusions in the paper are present in the paper or the Supplementary Materials. 


\section{References}

1. S. J. Schuster, M. R. Bishop, C. S. Tam, E. K. Waller, P. Borchmann, J. P. McGuirk, U. Jäger, S. Jaglowski, C. Andreadis, J. R. Westin, I. Fleury, V. Bachanova, S. R. Foley, P. J. Ho, S. Mielke, J. M. Magenau, H. Holte, S. Pantano, L. B. Pacaud, R. Awasthi, J. Chu, Ö. Anak, G. Salles, R. T. Maziarz, Tisagenlecleucel in Adult Relapsed or Refractory Diffuse Large B-Cell Lymphoma. New England Journal of Medicine. 380, 45-56 (2019).

2. C. H. June, M. Sadelain, Chimeric Antigen Receptor Therapy. New England Journal of Medicine. 379, 64-73 (2018).

3. S. S. Neelapu, F. L. Locke, N. L. Bartlett, L. J. Lekakis, D. B. Miklos, C. A. Jacobson, I. Braunschweig, O. O. Oluwole, T. Siddiqi, Y. Lin, J. M. Timmerman, P. J. Stiff, J. W. Friedberg, I. W. Flinn, A. Goy, B. T. Hill, M. R. Smith, A. Deol, U. Farooq, P. McSweeney, J. Munoz, I. Avivi, J. E. Castro, J. R. Westin, J. C. Chavez, A. Ghobadi, K. V. Komanduri, R. Levy, E. D. Jacobsen, T. E. Witzig, P. Reagan, A. Bot, J. Rossi, L. Navale, Y. Jiang, J. Aycock, M. Elias, D. Chang, J. Wiezorek, W. Y. Go, Axicabtagene Ciloleucel CAR T-Cell Therapy in Refractory Large B-Cell Lymphoma. http://dx.doi.org/10.1056/NEJMoa1707447 (2017), , doi:10.1056/NEJMoa1707447.

4. S. J. Schuster, J. Svoboda, E. A. Chong, S. D. Nasta, A. R. Mato, Ö. Anak, J. L. Brogdon, I. Pruteanu-Malinici, V. Bhoj, D. Landsburg, M. Wasik, B. L. Levine, S. F. Lacey, J. J. Melenhorst, D. L. Porter, C. H. June, Chimeric Antigen Receptor T Cells in Refractory BCell Lymphomas. http://dx.doi.org/10.1056/NEJMoal708566 (2017), doi:10.1056/NEJMoa1708566.

5. R. Awasthi, L. Pacaud, E. Waldron, C. S. Tam, U. Jäger, P. Borchmann, S. Jaglowski, S. R. Foley, K. van Besien, N. D. Wagner-Johnston, M. J. Kersten, S. J. Schuster, G. Salles, R. T. Maziarz, Ö. Anak, C. del Corral, J. Chu, I. Gershgorin, I. Pruteanu-Malinici, A. Chakraborty, 
K. T. Mueller, E. K. Waller, Tisagenlecleucel cellular kinetics, dose, and immunogenicity in relation to clinical factors in relapsed/refractory DLBCL. Blood Adv. 4, 560-572 (2020).

6. J. N. Kochenderfer, M. E. Dudley, S. A. Feldman, W. H. Wilson, D. E. Spaner, I. Maric, M. Stetler-Stevenson, G. Q. Phan, M. S. Hughes, R. M. Sherry, J. C. Yang, U. S. Kammula, L. Devillier, R. Carpenter, D.-A. N. Nathan, R. A. Morgan, C. Laurencot, S. A. Rosenberg, B-cell depletion and remissions of malignancy along with cytokine-associated toxicity in a clinical trial of anti-CD19 chimeric-antigen-receptor-transduced T cells. Blood. 119, 2709-2720 (2012).

7. P. S. Adusumilli, L. Cherkassky, J. Villena-Vargas, C. Colovos, E. Servais, J. Plotkin, D. R. Jones, M. Sadelain, Regional delivery of mesothelin-targeted CAR T cell therapy generates potent and long-lasting CD4-dependent tumor immunity. Science Translational Medicine. 6, 261ra151-261ra151 (2014).

8. E. Cheadle, R. Hawkins, H. Batha, D. Rothwell, G. Ashton, D. Gilham, Eradication of Established B-cell Lymphoma by CD19-specific Murine T Cells is Dependent on Host Lymphopenic Environment and Can be Mediated by CD4+ and CD8+ T Cells. Journal of Immunotherapy. 32, 207-218 (2009).

9. I. Liadi, H. Singh, G. Romain, N. Rey-Villamizar, A. Merouane, J. R. T. Adolacion, P. Kebriaei, H. Huls, P. Qiu, B. Roysam, L. J. N. Cooper, N. Varadarajan, Individual Motile CD4+ T Cells Can Participate in Efficient Multikilling through Conjugation to Multiple Tumor Cells. Cancer Immunol Res. 3, 473-482 (2015).

10. H. J. Pegram, J. C. Lee, E. G. Hayman, G. H. Imperato, T. F. Tedder, M. Sadelain, R. J. Brentjens, Tumor-targeted T cells modified to secrete IL-12 eradicate systemic tumors without need for prior conditioning. Blood. 119, 4133-4141 (2012).

11. D. Sommermeyer, M. Hudecek, P. L. Kosasih, T. Gogishvili, D. G. Maloney, C. J. Turtle, S. R. Riddell, Chimeric antigen receptor-modified T cells derived from defined CD8 + 
and CD4 + subsets confer superior antitumor reactivity in vivo. Leukemia. 30, 492-500 (2016).

12. D. Wang, B. Aguilar, R. Starr, D. Alizadeh, A. Brito, A. Sarkissian, J. R. Ostberg, S. J. Forman, C. E. Brown, Glioblastoma-targeted $\mathrm{CD}^{+}{ }^{+} \mathrm{CAR}$ T cells mediate superior antitumor activity. JCI Insight. 3 (2018), doi:10.1172/jci.insight.99048.

13. I. Xhangolli, B. Dura, G. Lee, D. Kim, Y. Xiao, R. Fan, Single-cell Analysis of CAR-T Cell Activation Reveals A Mixed TH1/TH2 Response Independent of Differentiation. Genomics, Proteomics \& Bioinformatics. 17, 129-139 (2019).

14. Y. Yang, M. E. Kohler, C. D. Chien, C. T. Sauter, E. Jacoby, C. Yan, Y. Hu, K. Wanhainen, H. Qin, T. J. Fry, TCR engagement negatively affects CD8 but not CD4 CAR T cell expansion and leukemic clearance. Science Translational Medicine. 9 (2017), doi:10.1126/scitranslmed.aag1209.

15. M. Cazaux, C. L. Grandjean, F. Lemaître, Z. Garcia, R. J. Beck, I. Milo, J. Postat, J. B. Beltman, E. J. Cheadle, P. Bousso, Journal of Experimental Medicine, in press, doi:10.1084/jem.20182375.

16. J. M. Adams, A. W. Harris, C. A. Pinkert, L. M. Corcoran, W. S. Alexander, S. Cory, R. D. Palmiter, R. L. Brinster, The c- myc oncogene driven by immunoglobulin enhancers induces lymphoid malignancy in transgenic mice. Nature. 318, 533-538 (1985).

17. A. W. Harris, The E mu-myc transgenic mouse. A model for high-incidence spontaneous lymphoma and leukemia of early B cells. J Exp Med. 167, 353-371 (1988).

18. B. Breart, F. Lemaître, S. Celli, P. Bousso, Two-photon imaging of intratumoral CD $8^{+}$ T cell cytotoxic activity during adoptive T cell therapy in mice. J Clin Invest. 118, 1390-1397 (2008).

19. D. Michonneau, P. Sagoo, B. Breart, Z. Garcia, S. Celli, P. Bousso, The PD-1 Axis Enforces an Anatomical Segregation of CTL Activity that Creates Tumor Niches after Allogeneic Hematopoietic Stem Cell Transplantation. Immunity. 44, 143-154 (2016). 
20. R. Thibaut, P. Bost, I. Milo, M. Cazaux, F. Lemaître, Z. Garcia, I. Amit, B. Breart, C. Cornuot, B. Schwikowski, P. Bousso, Bystander IFN- $\gamma$ activity promotes widespread and sustained cytokine signaling altering the tumor microenvironment. Nat Cancer. 1, 302-314 (2020).

21. M. E. Hoekstra, L. Bornes, F. E. Dijkgraaf, D. Philips, I. N. Pardieck, M. Toebes, D. S. Thommen, J. van Rheenen, T. N. M. Schumacher, Long-distance modulation of bystander tumor cells by CD8 + T-cell-secreted IFN- $\gamma$. Nat Cancer. 1, 291-301 (2020).

22. C.-C. S. Pai, J. T. Huang, X. Lu, D. M. Simons, C. Park, A. Chang, W. Tamaki, E. Liu, K. T. Roybal, J. Seagal, M. Chen, K. Hagihara, X. X. Wei, M. DuPage, S. S. Kwek, D. Y. Oh, A. Daud, K. K. Tsai, C. Wu, L. Zhang, M. Fasso, R. Sachidanandam, A. Jayaprakash, I. Lin, A.-J. Casbon, G. A. Kinsbury, L. Fong, Clonal Deletion of Tumor-Specific T Cells by Interferon- $\gamma$ Confers Therapeutic Resistance to Combination Immune Checkpoint Blockade. Immunity. 50, 477-492.e8 (2019).

23. M. P. Colombo, G. Trinchieri, Interleukin-12 in anti-tumor immunity and immunotherapy. Cytokine \& Growth Factor Reviews. 13, 155-168 (2002).

24. D. A. A. Vignali, V. K. Kuchroo, IL-12 family cytokines: immunological playmakers. Nature Immunology. 13, 722-728 (2012).

25. C. S. Garris, S. P. Arlauckas, R. H. Kohler, M. P. Trefny, S. Garren, C. Piot, C. Engblom, C. Pfirschke, M. Siwicki, J. Gungabeesoon, G. J. Freeman, S. E. Warren, S. Ong, E. Browning, C. G. Twitty, R. H. Pierce, M. H. Le, A. P. Algazi, A. I. Daud, S. I. Pai, A. Zippelius, R. Weissleder, M. J. Pittet, Successful Anti-PD-1 Cancer Immunotherapy Requires T CellDendritic Cell Crosstalk Involving the Cytokines IFN- $\gamma$ and IL-12. Immunity. 49, 1148-1161.e7 (2018).

26. H. J. Ramos, A. M. Davis, A. G. Cole, J. D. Schatzle, J. Forman, J. D. Farrar, Reciprocal responsiveness to interleukin-12 and interferon- $\alpha$ specifies human CD8+ effector versus central 
memory T-cell fates. Blood. 113, 5516-5525 (2009).

27. S. Chouaib, J. Chehimi, L. Bani, N. Genetet, T. Tursz, F. Gay, G. Trinchieri, F. MamiChouaib, Interleukin 12 induces the differentiation of major histocompatibility complex class I-primed cytotoxic T-lymphocyte precursors into allospecific cytotoxic effectors. PNAS. 91, 12659-12663 (1994).

28. M. P. Rubinstein, E. W. Su, S. Suriano, C. A. Cloud, K. Andrijauskaite, P. Kesarwani, K. M. Schwartz, K. M. Williams, C. B. Johnson, M. Li, G. M. Scurti, M. L. Salem, C. M. Paulos, E. Garrett-Mayer, S. Mehrotra, D. J. Cole, Interleukin-12 enhances the function and anti-tumor activity in murine and human CD8+ T cells. Cancer Immunol Immunother. 64, 539$549(2015)$.

29. I. Etxeberria, E. Bolaños, J. I. Quetglas, A. Gros, A. Villanueva, J. Palomero, A. R. Sánchez-Paulete, J. M. Piulats, X. Matias-Guiu, I. Olivera, M. C. Ochoa, S. Labiano, S. Garasa, I. Rodriguez, A. Vidal, U. Mancheño, S. Hervás-Stubbs, A. Azpilikueta, I. Otano, M. A. Aznar, M. F. Sanmamed, S. Inogés, P. Berraondo, Á. Teijeira, I. Melero, Intratumor Adoptive Transfer of IL-12 mRNA Transiently Engineered Antitumor CD8+ T Cells. Cancer Cell. 36, 613-629.e7 (2019).

30. S. A. Fuertes Marraco, F. Grosjean, A. Duval, M. Rosa, C. Lavanchy, D. Ashok, S. Haller, L. A. Otten, Q.-G. Steiner, P. Descombes, C. A. Luber, F. Meissner, M. Mann, L. Szeles, W. Reith, H. Acha-Orbea, Novel Murine Dendritic Cell Lines: A Powerful Auxiliary Tool for Dendritic Cell Research. Front Immunol. 3 (2012), doi:10.3389/fimmu.2012.00331.

31. R. A. Gardner, O. Finney, C. Annesley, H. Brakke, C. Summers, K. Leger, M. Bleakley, C. Brown, S. Mgebroff, K. S. Kelly-Spratt, V. Hoglund, C. Lindgren, A. P. Oron, D. Li, S. R. Riddell, J. R. Park, M. C. Jensen, Intent-to-treat leukemia remission by CD19 CAR T cells of defined formulation and dose in children and young adults. Blood. 129, 3322-3331 (2017).

32. C. J. Turtle, L.-A. Hanafi, C. Berger, T. A. Gooley, S. Cherian, M. Hudecek, D. 
Sommermeyer, K. Melville, B. Pender, T. M. Budiarto, E. Robinson, N. N. Steevens, C. Chaney, L. Soma, X. Chen, C. Yeung, B. Wood, D. Li, J. Cao, S. Heimfeld, M. C. Jensen, S. R. Riddell, D. G. Maloney, CD19 CAR-T cells of defined $\mathrm{CD} 4^{+}: \mathrm{CD}^{+}$composition in adult B cell ALL patients. J Clin Invest. 126, 2123-2138 (2016).

33. C. J. Turtle, L.-A. Hanafi, C. Berger, M. Hudecek, B. Pender, E. Robinson, R. Hawkins, C. Chaney, S. Cherian, X. Chen, L. Soma, B. Wood, D. Li, S. Heimfeld, S. R. Riddell, D. G. Maloney, Immunotherapy of non-Hodgkin lymphoma with a defined ratio of CD8+ and CD4+ CD19-specific chimeric antigen receptor-modified T cells. Sci Transl Med. 8, 355ra116 (2016). 34. S. A. Quezada, T. R. Simpson, K. S. Peggs, T. Merghoub, J. Vider, X. Fan, R. Blasberg, H. Yagita, P. Muranski, P. A. Antony, N. P. Restifo, J. P. Allison, Tumor-reactive CD4+ T cells develop cytotoxic activity and eradicate large established melanoma after transfer into lymphopenic hosts. $J$ Exp Med. 207, 637-650 (2010).

35. V. Shankaran, H. Ikeda, A. T. Bruce, J. M. White, P. E. Swanson, L. J. Old, R. D. Schreiber, IFN $\gamma$ and lymphocytes prevent primary tumour development and shape tumour immunogenicity. Nature. 410, 1107-1111 (2001).

36. B. Zhang, T. Karrison, D. A. Rowley, H. Schreiber, IFN- $\gamma-$ and TNF-dependent bystander eradication of antigen-loss variants in established mouse cancers. J Clin Invest. 118, 1398-1404 (2008).

37. A. Barber, C. L. Sentman, Chimeric NKG2D T Cells Require Both T Cell- and HostDerived Cytokine Secretion and Perforin Expression to Increase Tumor Antigen Presentation and Systemic Immunity. The Journal of Immunology. 183, 2365-2372 (2009).

38. A. Barber, A. Rynda, C. L. Sentman, Chimeric NKG2D Expressing T Cells Eliminate Immunosuppression and Activate Immunity within the Ovarian Tumor Microenvironment. The Journal of Immunology. 183, 6939-6947 (2009).

39. A. Textor, J. J. Listopad, L. L. Wührmann, C. Perez, A. Kruschinski, M. Chmielewski, 
H. Abken, T. Blankenstein, J. Charo, Efficacy of CAR T-cell Therapy in Large Tumors Relies upon Stromal Targeting by IFN $\gamma$. Cancer Res. 74, 6796-6805 (2014).

40. H. Braumüller, T. Wieder, E. Brenner, S. Aßmann, M. Hahn, M. Alkhaled, K. Schilbach, F. Essmann, M. Kneilling, C. Griessinger, F. Ranta, S. Ullrich, R. Mocikat, K. Braungart, T. Mehra, B. Fehrenbacher, J. Berdel, H. Niessner, F. Meier, M. van den Broek, H.U. Häring, R. Handgretinger, L. Quintanilla-Martinez, F. Fend, M. Pesic, J. Bauer, L. Zender, M. Schaller, K. Schulze-Osthoff, M. Röcken, T-helper-1-cell cytokines drive cancer into senescence. Nature. 494, 361-365 (2013).

41. A. S. Dighe, E. Richards, L. J. Old, R. D. Schreiber, Enhanced in vivo growth and resistance to rejection of tumor cells expressing dominant negative IFN $\gamma$ receptors. Immunity. 1, 447-456 (1994).

42. T. Kammertoens, C. Friese, A. Arina, C. Idel, D. Briesemeister, M. Rothe, A. Ivanov, A. Szymborska, G. Patone, S. Kunz, D. Sommermeyer, B. Engels, M. Leisegang, A. Textor, H. J. Fehling, M. Fruttiger, M. Lohoff, A. Herrmann, H. Yu, R. Weichselbaum, W. Uckert, N. Hübner, H. Gerhardt, D. Beule, H. Schreiber, T. Blankenstein, Tumour ischaemia by interferon$\gamma$ resembles physiological blood vessel regression. Nature. 545, 98-102 (2017).

43. Z. Qin, T. Blankenstein, CD4+ T Cell-Mediated Tumor Rejection Involves Inhibition of Angiogenesis that Is Dependent on IFN $\gamma$ Receptor Expression by Nonhematopoietic Cells. Immunity. 12, 677-686 (2000).

44. P. Spear, A. Barber, A. Rynda-Apple, C. L. Sentman, Chimeric Antigen Receptor T Cells Shape Myeloid Cell Function within the Tumor Microenvironment through IFN- $\gamma$ and GM-CSF. The Journal of Immunology. 188, 6389-6398 (2012).

45. P. Spear, A. Barber, C. L. Sentman, Collaboration of chimeric antigen receptor (CAR)expressing $\mathrm{T}$ cells and host $\mathrm{T}$ cells for optimal elimination of established ovarian tumors. OncoImmunology. 2, e23564 (2013). 
46. M. Chmielewski, C. Kopecky, A. A. Hombach, H. Abken, IL-12 Release by Engineered T Cells Expressing Chimeric Antigen Receptors Can Effectively Muster an AntigenIndependent Macrophage Response on Tumor Cells That Have Shut Down Tumor Antigen Expression. Cancer Res. 71, 5697-5706 (2011).

47. M. Koneru, T. J. Purdon, D. Spriggs, S. Koneru, R. J. Brentjens, IL-12 secreting tumortargeted chimeric antigen receptor T cells eradicate ovarian tumors in vivo. Oncolmmunology. 4, e994446 (2015).

48. G. Kueberuwa, M. Kalaitsidou, E. Cheadle, R. E. Hawkins, D. E. Gilham, CD19 CAR T Cells Expressing IL-12 Eradicate Lymphoma in Fully Lymphoreplete Mice through Induction of Host Immunity. Molecular Therapy - Oncolytics. 8, 41-51 (2018).

49. O. O. Yeku, T. J. Purdon, M. Koneru, D. Spriggs, R. J. Brentjens, Armored CAR T cells enhance antitumor efficacy and overcome the tumor microenvironment. Sci Rep. 7, 1-14 (2017).

50. V. Hoyos, B. Savoldo, C. Quintarelli, A. Mahendravada, M. Zhang, J. Vera, H. E. Heslop, C. M. Rooney, M. K. Brenner, G. Dotti, Engineering CD19-specific T lymphocytes with interleukin-15 and a suicide gene to enhance their anti-lymphoma/leukemia effects and safety. Leukemia. 24, 1160-1170 (2010).

51. M. P. Avanzi, O. Yeku, X. Li, D. P. Wijewarnasuriya, D. G. van Leeuwen, K. Cheung, H. Park, T. J. Purdon, A. F. Daniyan, M. H. Spitzer, R. J. Brentjens, Engineered TumorTargeted T Cells Mediate Enhanced Anti-Tumor Efficacy Both Directly and through Activation of the Endogenous Immune System. Cell Reports. 23, 2130-2141 (2018).

52. K. Adachi, Y. Kano, T. Nagai, N. Okuyama, Y. Sakoda, K. Tamada, IL-7 and CCL19 expression in CAR-T cells improves immune cell infiltration and CAR-T cell survival in the tumor. Nat Biotechnol. 36, 346-351 (2018).

53. L. Ma, T. Dichwalkar, J. Y. H. Chang, B. Cossette, D. Garafola, A. Q. Zhang, M. 
Fichter, C. Wang, S. Liang, M. Silva, S. Kumari, N. K. Mehta, W. Abraham, N. Thai, N. Li, K.

D. Wittrup, D. J. Irvine, Enhanced CAR-T cell activity against solid tumors by vaccine boosting through the chimeric receptor. Science. 365, 162-168 (2019).

54. J. H. Sampson, B. D. Choi, L. Sanchez-Perez, C. M. Suryadevara, D. J. Snyder, C. T. Flores, R. J. Schmittling, S. K. Nair, E. A. Reap, P. K. Norberg, J. E. Herndon, C.-T. Kuan, R. A. Morgan, S. A. Rosenberg, L. A. Johnson, EGFRvIII mCAR-Modified T-Cell Therapy Cures Mice with Established Intracerebral Glioma and Generates Host Immunity against TumorAntigen Loss. Clin Cancer Res. 20, 972-984 (2014).

55. R. G. Majzner, C. L. Mackall, Tumor Antigen Escape from CAR T-cell Therapy. Cancer Discov. 8, 1219-1226 (2018).

56. H. Shalabi, I. L. Kraft, H.-W. Wang, C. M. Yuan, B. Yates, C. Delbrook, J. D. Zimbelman, R. Giller, M. Stetler-Stevenson, E. S. Jaffe, D. W. Lee, J. F. Shern, T. J. Fry, N. N. Shah, Sequential loss of tumor surface antigens following chimeric antigen receptor T-cell therapies in diffuse large B-cell lymphoma. Haematologica. 103, e215-e218 (2018).

57. H. Yu, E. Sotillo, C. Harrington, G. Wertheim, M. Paessler, S. L. Maude, S. R. Rheingold, S. A. Grupp, A. Thomas- Tikhonenko, V. Pillai, Repeated loss of target surface antigen after immunotherapy in primary mediastinal large B cell lymphoma. American Journal of Hematology. 92, E11-E13 (2017).

58. I. Milo, M. Bedora-Faure, Z. Garcia, R. Thibaut, L. Périé, G. Shakhar, L. Deriano, P. Bousso, The immune system profoundly restricts intratumor genetic heterogeneity. Science Immunology. 3 (2018), doi:10.1126/sciimmunol.aat1435.

59. E. J. Cheadle, V. Sheard, D. G. Rothwell, J. S. Bridgeman, G. Ashton, V. Hanson, A. W. Mansoor, R. E. Hawkins, D. E. Gilham, Differential Role of Th1 and Th2 Cytokines in Autotoxicity Driven by CD19-Specific Second-Generation Chimeric Antigen Receptor T Cells in a Mouse Model. The Journal of Immunology. 192, 3654-3665 (2014). 
60. K. Andrijauskaite, S. Suriano, C. A. Cloud, M. Li, P. Kesarwani, L. S. Stefanik, K. M. Moxley, M. L. Salem, E. Garrett-Mayer, C. M. Paulos, S. Mehrotra, J. N. Kochenderfer, D. J. Cole, M. P. Rubinstein, IL-12 conditioning improves retrovirally mediated transduction efficiency of CD8 + T cells. Cancer Gene Ther. 22, 360-367 (2015).

61. J. N. Kochenderfer, Z. Yu, D. Frasheri, N. P. Restifo, S. A. Rosenberg, Adoptive transfer of syngeneic $\mathrm{T}$ cells transduced with a chimeric antigen receptor that recognizes murine CD19 can eradicate lymphoma and normal B cells. Blood. 116, 3875-3886 (2010).

62. P. Bousso, A. Casrouge, J. D. Altman, M. Haury, J. Kanellopoulos, J.-P. Abastado, P. Kourilsky, Individual Variations in the Murine T Cell Response to a Specific Peptide Reflect Variability in Naive Repertoires. Immunity. 9, 169-178 (1998).

63. H. D. Moreau, F. Lemaître, E. Terriac, G. Azar, M. Piel, A.-M. Lennon-Dumenil, P. Bousso, Dynamic In Situ Cytometry Uncovers $\mathrm{T}$ Cell Receptor Signaling during Immunological Synapses and Kinapses In Vivo. Immunity. 37, 351-363 (2012).

64. A. Butler, P. Hoffman, P. Smibert, E. Papalexi, R. Satija, Integrating single-cell transcriptomic data across different conditions, technologies, and species. Nat Biotechnol. 36, $411-420(2018)$. 


\section{Figure legends}

Figure 1. CAR8 T cells exhibit superior killing capacity compared to CAR4 T cells in vivo in a model of MYC-driven B cell lymphoma.

E $\mu$-myc B cell lymphoma was established by i.v. injection of $0.5 \times 10^{6}$ E $\mu$-myc-DEVD cells in C57BL/6 mice after sublethal irradiation (4 Gy). Six days later, mice were injected i.v. with 20x10 $10^{6}$ GPP-expressing CAR4 or CAR8 T cells. (A) Representative two-photon images of the bone marrow at days 3 and 5 after CAR4 or CAR8 T cell transfer showing that near-complete tumor eradication is seen only upon CAR8 T cell injection. T cells are shown in green, live tumor cells in white, and apoptotic tumor cells in blue. Scale bar, $100 \mu \mathrm{m}$. Inset scale bar, 30 $\mu \mathrm{m}$. Representative of at least three independent experiments. (B) Assessment of spatial correlation between apoptotic tumors (blue) and CAR T cells (green) within the bone marrow 3 days post CAR $\mathrm{T}$ cell transfer. For each region of interest (ROI) of 100x100 $\mu \mathrm{m}$, the mean blue and green values were computed as a proxy for apoptotic tumor and CAR T cell presence, respectively. Data are representative of 3 independent experiments. Spearman's correlation coefficients are shown. (C) Quantification of tumor apoptotic events from intravital real-time imaging using a FRET-based genetically encoded caspase-3 reporter. Apoptotic events were classified as direct killing when a CAR $\mathrm{T}$ cell engaged the tumor cell before FRET loss detection. Indirect events corresponded to tumor cells undergoing FRET loss without any apparent interactions with a CAR T cell. Data are compiled from movies performed 2 to 6 days after CAR T cell transfer (representing 65 and 43 hours of imaging for CAR4 and CAR8 T cells, respectively) from four independent experiments. Two-way analysis of variance (ANOVA) was used for statistical analysis. (D) Representative two-photon time-lapse images illustrating direct and indirect tumor apoptotic events mediated by CAR4 or CAR8 T cells. Red 
arrowheads highlight CAR T cells involved in killing. White dotted circles highlight tumor cells undergoing apoptosis. Scale bars, $10 \mu \mathrm{m}$. (E-G) Bone marrow composition was analyzed ex vivo by flow cytometry 3 days after T cell transfer. (E) Summary graph showing the percentage of apoptotic tumor cells. (F) Percentage of tumor cells recovered (relative to untreated mice). (G) Bar chart showing CAR4 and CAR8 T cell accumulation within the bone marrow. Absolute number of CAR T cells recovered from the bone marrow of one tibia and one femur. Data shown in E-G are representative of at least three independent experiments. Each dot represents one mouse. Two-tailed Mann-Whitney U-test was used for statistical analysis. (H) CAR8 but not CAR4 $\mathrm{T}$ cell therapy prolonged mouse survival. Log-rank test was used for statistical analysis. Data are compiled from two independent experiments $(\mathrm{n}=12$ per group). ***, $\mathrm{p}<0.001 ; * *, \mathrm{p}<0.01 ;$ ns, not significant.

\section{Figure 2. Single-cell RNA sequencing reveals profound changes in the tumor microenvironment induced by CAR4 and CAR8 T cells.}

B cell lymphoma was established by i.v. injection of $0.5 \times 10^{6}$ E $\mu$-myc-DEVD cells in C57BL/6 mice after sublethal irradiation (4 Gy). Six days later, mice were injected i.v. with 20x10 $0^{6}$ GFPexpressing CAR4 or CAR8 T cells or left untreated. Bone marrow cells were harvested 3 days after initiation of therapy and subjected to single-cell RNA sequencing. (A) Uniform Manifold Approximation Projection (UMAP) feature plots showing the composition of the TME in untreated (left), CAR4 T cell-treated (middle) and CAR8 T cell-treated (right) mice. Clusters were assigned according to lineage defining factors (see Fig. S7). Expression of GFP and CAR transgene were used to identify $\mathrm{CAR} T$ cells in treated conditions. Baso/Masto: basophils/mastocytes; Mo/MØ: monocytes/macrophages; cDC1: conventional type 1 dendritic cells; pDC: plasmacytoid dendritic cells; NK: NK cells; T/NKT: T cells and NKT cells. $\mathrm{GFP}^{+} \mathrm{CAR}^{-}$cells correspond to residual, untransduced transferred T cells. (B) Volcano plots 
showing differentially expressed genes between CAR4 $\mathrm{T}$ cell-treated and untreated mice or between CAR8 T cell-treated and untreated mice in both NK cells (left) and T/NKT cells (right). Statistically significant genes (corrected $p$ value $<0.05$ ) are shown in red. Dotted black lines indicate $\log _{2}$ fold change $>1$ or $<-1$. Statistical significance was calculated using Wilcoxon test. (C) Feature plots highlighting the expression of cytotoxicity-related genes Gzmb (granzyme B), Gzma (granzyme A), Prfl (perforin) and Ifng (IFN- $\gamma$ ) across NK cell, T/NKT cell and CAR T cell clusters identified in (A). Gene expression is scaled from lowblue to high-red. (D) CAR T cell-induced modulation of antigen-presentation genes in the TME. Violin plots showing gene expression of MHC class II (H2Aa, H2Ab1) and CD74 genes in various immune cell clusters (cDC1: conventional type 1 dendritic cells; pDC: plasmacytoid dendritic cells; Mo/MØ: monocytes/macrophages) and tumor cells. Boxplots show medians and interquartile ranges. Wilcoxon test and Bonferroni method for $p$ value correction were used.

Figure 3. CAR T cells promote host immune cell recruitment and activation at the tumor site.

(A-D) B cell lymphoma was established by i.v. injection of $0.5 \times 10^{6} \mathrm{E} \mu$-myc-DEVD cells in C57BL/6 mice after sublethal irradiation (4 Gy). Six days later, mice were injected i.v. with 20x $10^{6}$ CAR4 or CAR8 T cells or left untreated. After 3 days, the bone marrow was harvested and analyzed by flow cytometry. (A) Percentage of NK1.1 $1^{+}$cells, $\mathrm{CD}^{+} \mathrm{T}$ cells, $\mathrm{CD} 4^{+} \mathrm{T}$ cells, dendritic cells $\left(\mathrm{CD} 11 \mathrm{c}^{+} \mathrm{I}-\mathrm{A} / \mathrm{I}-\mathrm{E}^{+}\right)$and monocytes $\left(\mathrm{CD} 11 \mathrm{~b}^{+}\right.$Ly6G- $\left.\mathrm{Ly}^{-} \mathrm{C}^{+}\right)$recovered. (B-D) Activation of endogenous effector cells upon CAR T cell therapy. Representative histograms (upper panels) and compiled quantifications (lower graphs) showing intracellular granzyme B expression in NK1.1 $1^{+}$cells $(\mathbf{B})$ and $\mathrm{CD}^{+} \mathrm{T}$ cells $(\mathbf{C})$ as well as MHC class II (I-A/I-E) surface expression on monocytes (D). Data shown in A-D are pooled from at least two independent experiments. Each dot represents one mouse. Two-tailed Mann-Whitney U-test was used for 
statistical analysis. (E) C57BL/6 mice were injected i.v. with $0.5 \times 10^{6}$ OVA-expressing E $\mu$ myc lymphoma cells. Six days later, mice were injected i.v. with $10 \times 10^{6}$ CAR4 or CAR8 T cells. Anti-CD20 antibody was injected 2 days before CAR T cell transfer as a conditioning regimen. Graphs show the percentage of OVA-specific $\mathrm{CD}^{+} \mathrm{T}$ cells on day 5 as assessed by tetramer staining upon CAR T cell therapy in the bone marrow (left) and in blood (right). Data are representative of two independent experiments. Each dot represents one mouse. Unpaired t test was used for statistical analysis. ${ }^{* *}, \mathrm{p}<0.001 ;{ }^{* *}, \mathrm{p}<0.01 ;{ }^{*}, \mathrm{p}<0.05$; ns, not significant.

Figure 4. CAR $T$ cell-derived IFN- $\gamma$ mediates widespread changes in the tumor microenvironment.

(A-B) B cell lymphoma was established by i.v. injection of $0.5 \times 10^{6}$ E $\mu$-myc cells in C57BL/6 mice after sublethal irradiation (4 Gy). Six days later, mice were injected i.v. with $20 \times 10^{6}$ CAR4 or CAR8 T cells or left untreated. Bone marrow cells were harvested 3 days after initiation of therapy. (A) Detection of an IFN signature in the TME upon CAR T cell therapy. Volcano plots of differentially expressed genes between CAR4 $\mathrm{T}$ cell-treated and untreated mice (left) and between CAR8 T cell-treated and untreated mice (right) in all cells but CAR T cells. Plots show the upregulation of many interferon-associated genes. Statistically significant genes (corrected $\mathrm{p}$ value $<0.05)$ are shown in red. Dotted black lines indicate $\log _{2}$ fold change $>1$ or $<-1$. Statistical significance was calculated using Wilcoxon test. (B) CAR T cell therapy increases widespread MHC class I expression in the TME. Violin plots showing the gene expression distribution of MHC class I genes $(H 2-D 1$ and $H 2-K 1)$ in various immune cell clusters (cDC1: conventional type 1 dendritic cells; $\mathrm{pDC}$ : plasmacytoid dendritic cells; Mo/MØ: monocytes/macrophages; NK: NK cells; T/NKT: T cells and NKT cells; Neutro: neutrophils) and tumor cells. Boxplots show medians and interquartile ranges. (C-D) CAR T cell-derived IFN- $\gamma$ increases MHC class I levels in tumor and tumor-infiltrating immune cells. Lymphoma- 
bearing mice were treated with $10 \times 10^{6} \mathrm{WT}$ or IFN- $\gamma$-deficient CAR4 or CAR8 T cells. Surface expression of $\mathrm{H} 2-\mathrm{D}^{\mathrm{b}}$ (left) and $\mathrm{H} 2-\mathrm{K}^{\mathrm{b}}$ (right) was assessed on $\mathrm{CD} 11 \mathrm{~b}^{+}$myeloid cells $(\mathbf{C})$ and tumor cells (D) on day 3. gMFI, geometric mean fluorescence intensity. Data in C-D are representative of two independent experiments. Each dot represents one mouse. Unpaired t test was used for statistical analysis. ${ }^{* *}, \mathrm{p}<0.001 ; * *, \mathrm{p}<0.01 ; *, \mathrm{p}<0.05$.

Figure 5. CAR T cell-derived IFN- $\gamma$ drives immune cell recruitment and activation at the tumor site.

B cell lymphoma was established by i.v. injection of $0.5 \times 10^{6} \mathrm{E} \mu$-myc cells in C57BL/6 mice after sublethal irradiation (4 Gy). Six days later, mice were injected i.v. with $10 \times 10^{6} \mathrm{WT}$ or IFN- $\gamma$-deficient CAR4 or CAR8 T cells or left untreated. After 3 days, the bone marrow was harvested and analyzed by flow cytometry. (A) Percentage of NK cells (NK1.1 ${ }^{+} \mathrm{CD}^{-}{ }^{-}$, NKT cells $\left(\mathrm{NK} 1.1^{+} \mathrm{CD}^{+}\right)$, dendritic cells $\left(\mathrm{CD} 11 \mathrm{c}^{+} \mathrm{I}-\mathrm{A} / \mathrm{I}-\mathrm{E}^{+}\right)$and monocytes $\left(\mathrm{CD} 11 \mathrm{~b}^{+} \mathrm{Ly}_{6 \mathrm{G}}^{-} \mathrm{Ly}_{6 \mathrm{C}^{+}}\right)$ recovered. (B-E) CAR T cell-derived IFN- $\gamma$ promotes immune cell activation. Representative histograms (upper panels) and quantifications (lower graphs) showing intracellular granzyme B expression in NK cells (B), NKT cells $(\mathbf{C}), \mathrm{CD}^{+} \mathrm{T}$ cells $(\mathbf{D})$ and MHC class II (I-A/I-E) surface expression on monocytes (E). (F) Representative histograms (left) and quantifications (right) showing intracellular granzyme B expression in CAR8 T cells within the bone marrow. Data in A-F are compiled from two_independent experiments. Each dot represents one mouse. Unpaired $\mathrm{t}$ test was used for statistical analysis. ***, $\mathrm{p}<0.001 ;{ }^{* *}, \mathrm{p}<0.01 ;{ }^{*}, \mathrm{p}<0.05$; ns, not significant.

Figure 6. Cytokine-mediated crosstalk between CAR $T$ cells and host cells is essential to sustain CAR T cell cytotoxicity. 
B cell lymphomas were established by i.v. injection of $0.5 \times 10^{6}$ E $\mu$-myc-DEVD cells in C57BL/6 or IFN- $\gamma$ R-deficient mice after sublethal irradiation (4 Gy). Six days later, mice were injected i.v. with $10 \times 10^{6} \mathrm{WT}$ or IFN- $\gamma^{-/-}$CAR8 T cells or left untreated. (A) Mouse survival for the indicated recipients and CAR T cell preparations. Log-rank test was used for statistical analysis. Data are compiled from four independent experiments $\underline{(\mathrm{n}=18-26 \text { mice per group })}$. (B) Percentage of intracellular granzyme B-expressing CAR T cells (left) and geometric mean fluorescence intensity in CAR T cells (right) on day 3 in C57BL/6 and IFN- $\gamma$ R-deficient mice. Data are compiled from two independent experiments. Each dot represents one mouse. Unpaired t test was used for statistical analysis. (C-H) Killing dynamics of WT or IFN- $\gamma-$ deficient CAR T cells was assessed by intravital imaging on day 5-6. (C) Representative twophoton images of tumor-bearing mice treated with WT or IFN- $\gamma$-deficient CAR8 T cells. T cells are shown in green, live tumor cells in white, and apoptotic tumor cells in blue. Scale bars, $30 \mu \mathrm{m}$. (D-E) Quantification of the surface occupied by CAR T cells in the region of interest (ROI) (D) and of the percentage of apoptotic tumors (ratio of the surface occupied by apoptotic tumors to the total surface occupied by tumor cells) (E). (F) An apoptosis index was calculated for WT and IFN- $\gamma$-deficient CAR T cells by normalizing the surface occupied by apoptotic tumors to the surface occupied by CAR T cells. (G) Quantification of tumor apoptotic events detected during the imaging period (normalized per hour per imaged surface). Apoptotic events were considered as direct killing when a CAR T cell engaged the tumor cell before FRET loss detection. Indirect events corresponded to tumor cells undergoing FRET loss without any detectable interactions with a CAR $T$ cell. A total of $n=21$ and $n=20$ apoptotic events were recorded for WT and IFN- $\gamma^{-/-}$CAR8 T cells, respectively. (H) A killing index was calculated for WT and IFN- $\gamma$-deficient CAR T cells as the ratio of direct apoptotic events to the surface occupied by CAR T cells in the image. Unpaired t test was used for statistical analysis. Data in C-H are compiled from movies performed 5 to 6 days after the transfer of WT CAR8 T cells ( $\mathrm{n}$ 
$=4$ mice, 38 hours of movie analyzed $)$ and IFN- $\gamma$-deficient CAR8 T cells $(n=4$ mice, 57 hours

of movie analyzed) from two independent experiments. Two-tailed Mann-Whitney U-test was used for statistical analysis. ${ }^{* * *}, \mathrm{p}<0.001 ; * *, \mathrm{p}<0.01 ; *, \mathrm{p}<0.05$; ns, not significant.

Figure 7. A role for the IFN- $\gamma / \mathrm{IL}-12$ axis in the interplay between $\mathrm{CAR} T$ cells and the tumor microenvironment.

(A) Detection of IL-12 expression in the TME of WT tumor-bearing mice upon CAR T cell therapy using single-cell RNA sequencing. Baso/Masto: basophils/mastocytes; cDC1: conventional type 1 dendritic cells; Mo/MØ: monocytes/macrophages; Neutro: neutrophils; NK: NK cells; pDC: plasmacytoid dendritic cells; T/NKT: T cells and NKT cells. $\mathrm{GFP}^{+} \mathrm{CAR}^{-}$cells correspond to residual, untransduced transferred $\mathrm{T}$ cells. (B-E) B cell lymphomas were established by i.v. injection of $0.5 \times 10^{6}$ E $\mu$-myc-DEVD cells in C57BL/ 6 or IL-12p35-deficient mice after sublethal irradiation (4 Gy). Six days later, mice were injected i.v. with $10 \times 10^{6} \mathrm{WT}$ or IFN- $\gamma^{-/-}$CAR $8 \mathrm{~T}$ cells or left untreated. When indicated, recombinant IL-12 was delivered daily intraperitoneally for 3 days starting at CAR T cell therapy. (B) Bone marrow cells were collected three days after CAR T cell transfer, and IL$12 \mathrm{p} 70$ and IFN- $\gamma$ production was measured by multiplex assay $(\mathrm{n}=5$ mice per group). (C) Percentage of granzyme B-expressing CAR8 T cells (left) and geometric mean fluorescence intensity (gMFI) within granzyme B-positive CAR8 T cells (right) on day 3. (D) Percentage of granzyme B-expressing CAR8 T cells (top) and geometric mean fluorescence intensity within granzyme B-positive CAR8 T cells (bottom) on day 3 in C57BL/6 and IL-12p35-deficient mice. (E) Intracellular granzyme B content in endogenous immune cells on day 3. (Upper panels) Percentage of granzyme B-expressing $\mathrm{CD}^{+} \mathrm{T}$ cells (left), NK cells (middle) and NKT cells (right). (Lower panels) Geometric mean fluorescence intensity in granzyme B-positive CD $8^{+} \mathrm{T}$ cells (left), NK cells (middle) and NKT cells (right). Data in D-E are representative of two 
independent experiments. Each dot represents one mouse. One-way ANOVA was used for statistical analysis. $* * *, p<0.001 ; * *, p<0.01 ; *, p<0.05 . ;$ ns, not significant. 
A

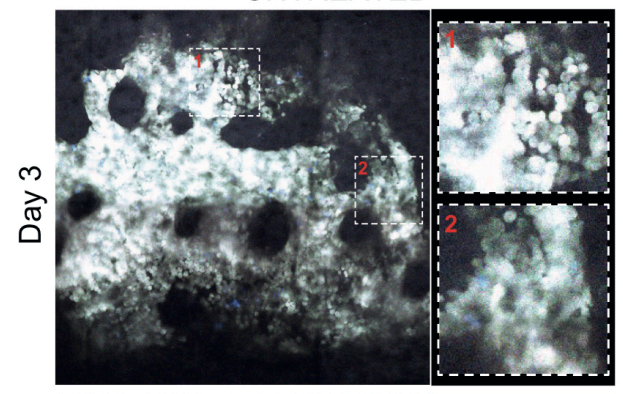

.

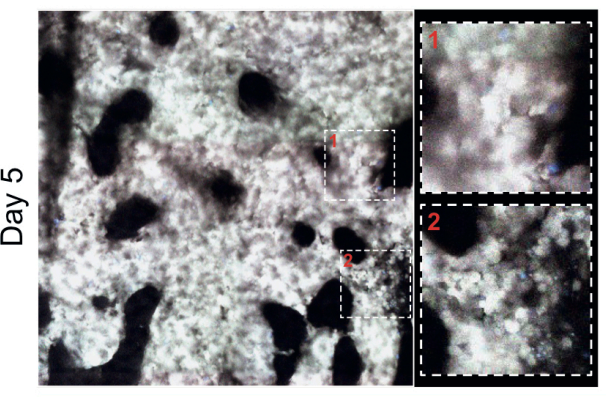

Live tumor cells

B

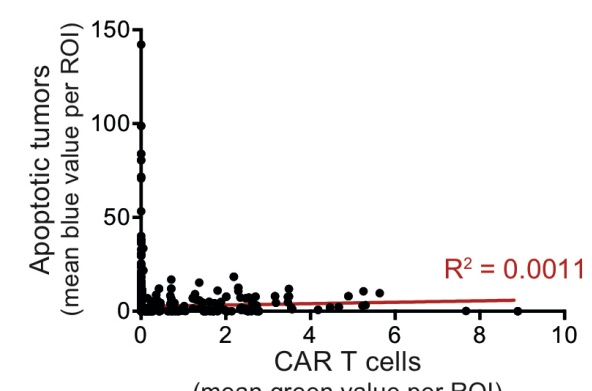

CAR4
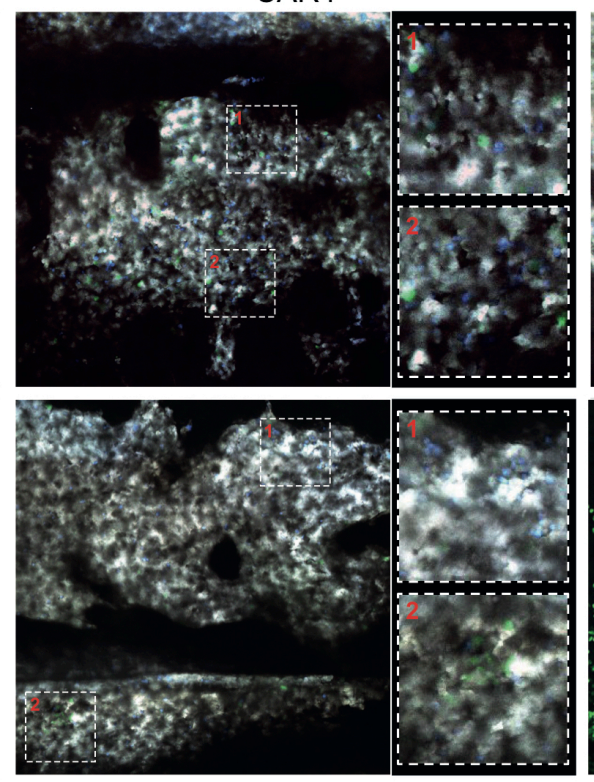

poptotic tumor cells
CAR8
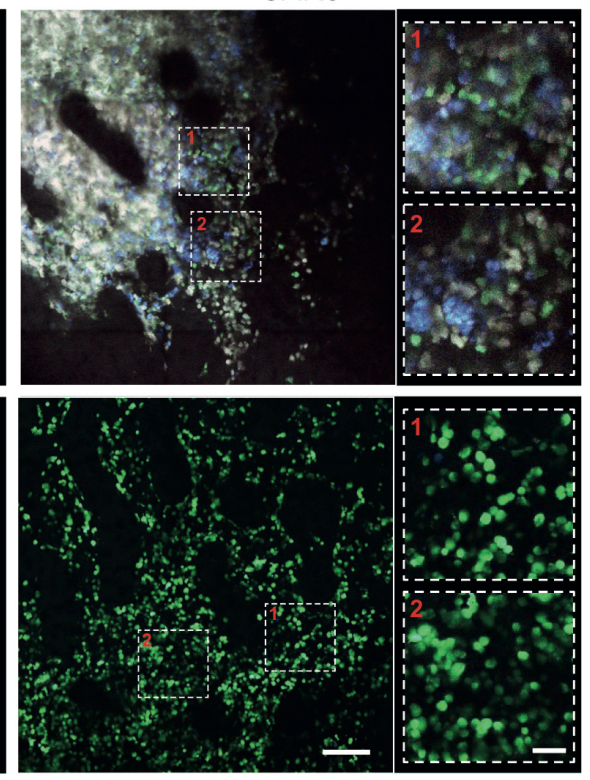

CAR T cells

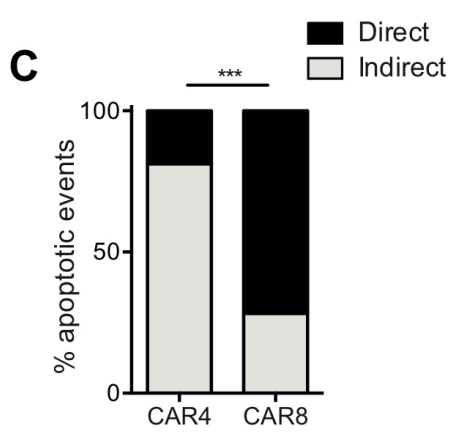

D
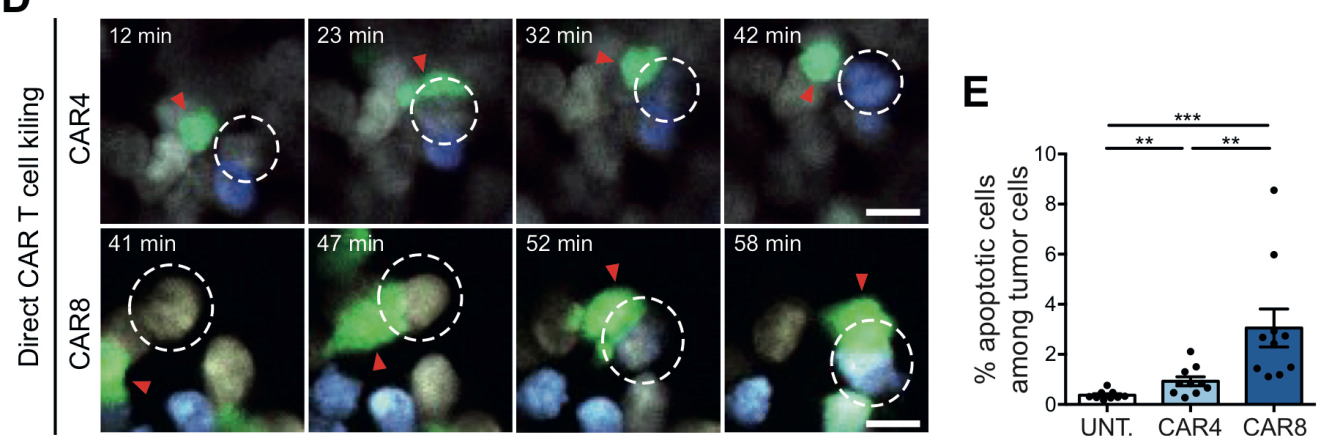

$\mathbf{F}$

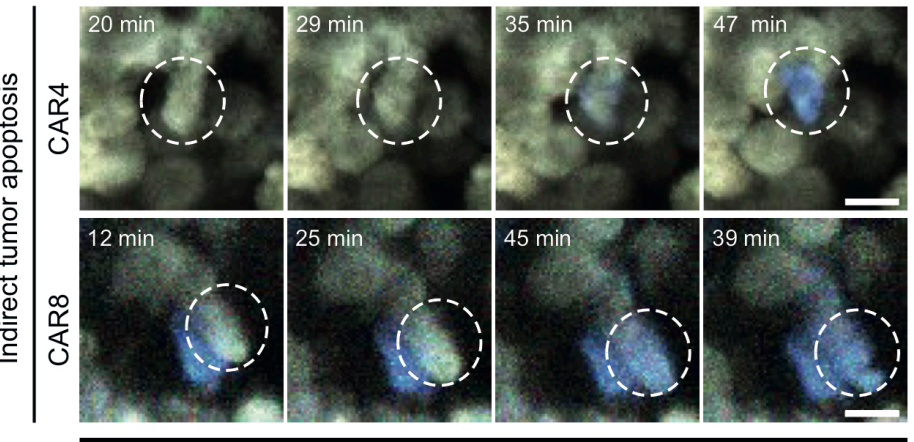

Live tumor cells

CAR T cells
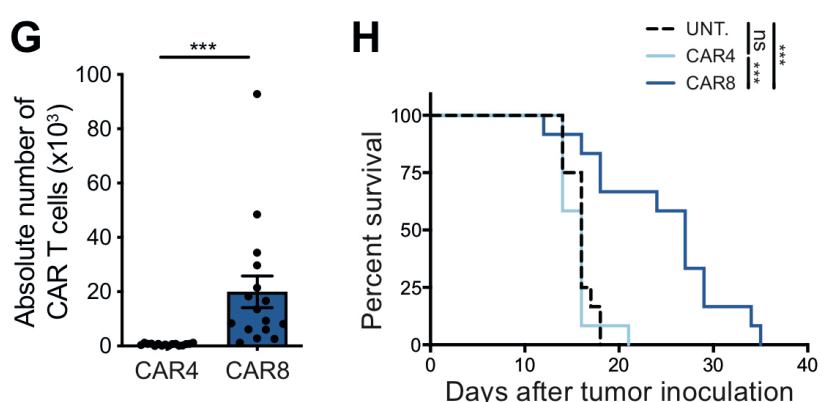

Figure 1 
A

Untreated
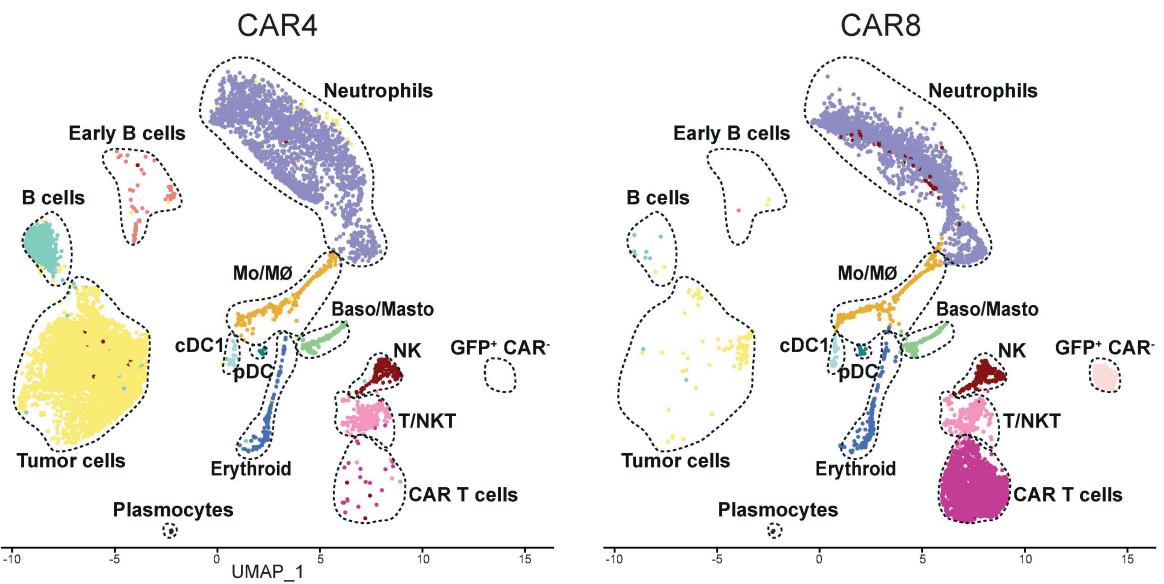

B

Cluster NK

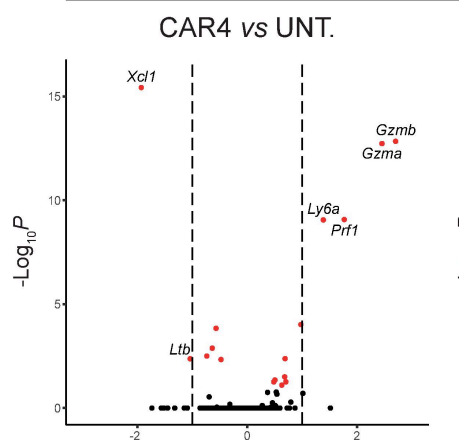

$\log _{2}$ fold change

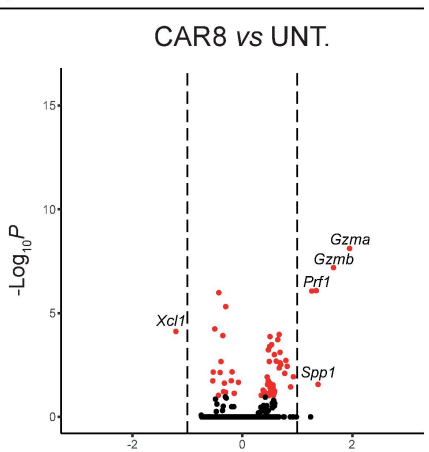

$\log _{2}$ fold change

C

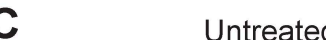

\section{CAR4 \\ CAR8}
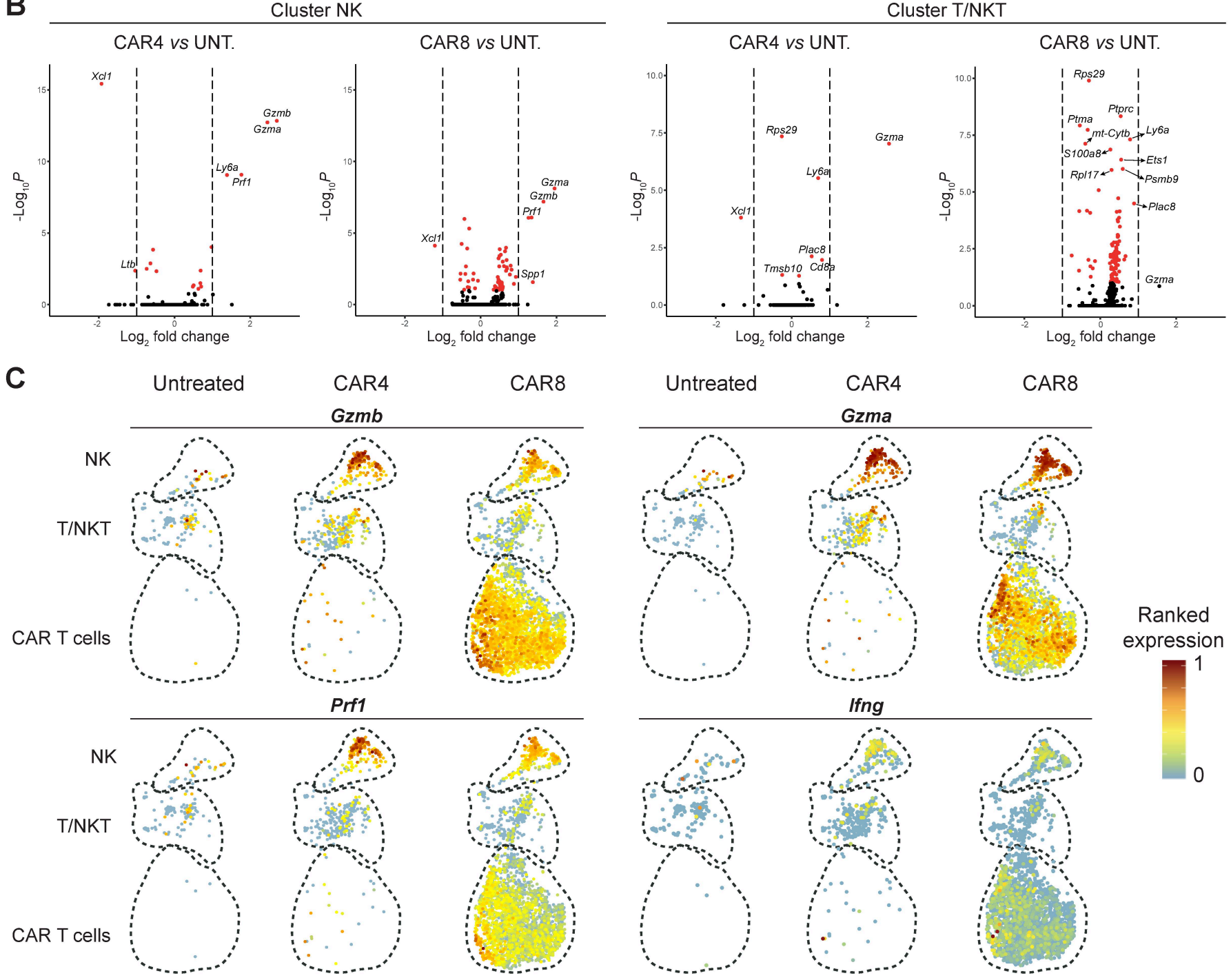

D
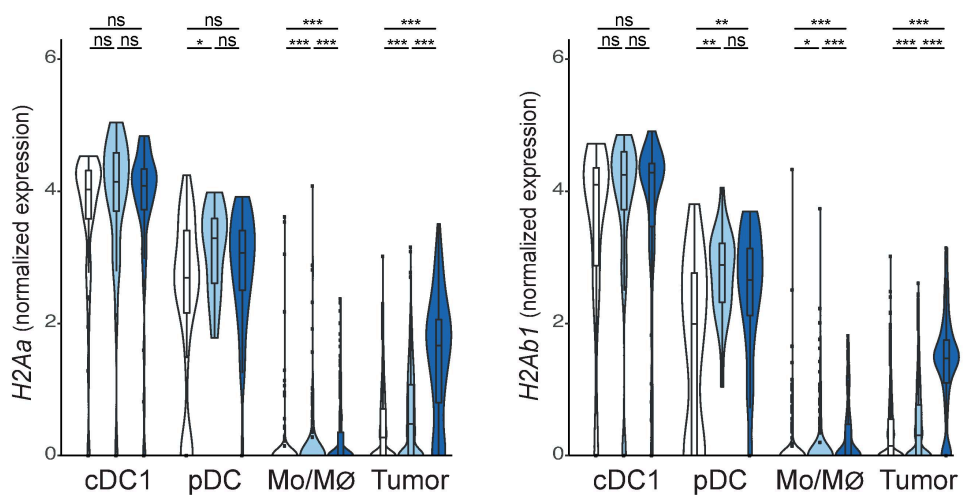

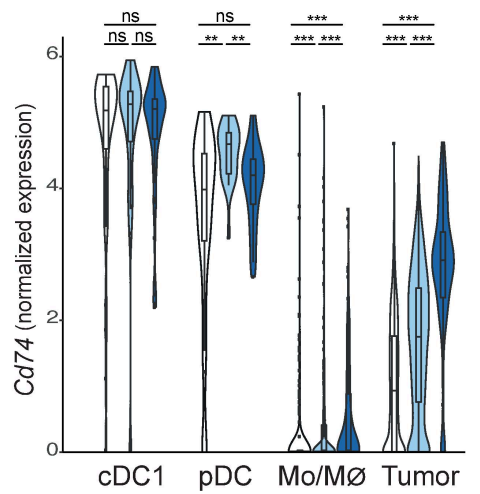

Ranked expression
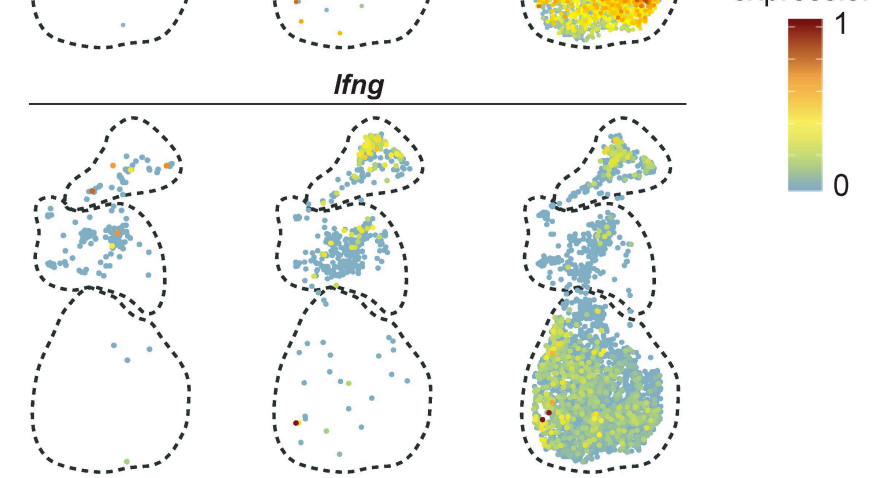

Mo/M $\varnothing$ Tumo 
A NK1.1+ cells

$\mathrm{CD}^{+} \mathrm{T}$ cells

$\mathrm{CD}^{+} \mathrm{T}$ cells

Dendritic cells

Monocytes
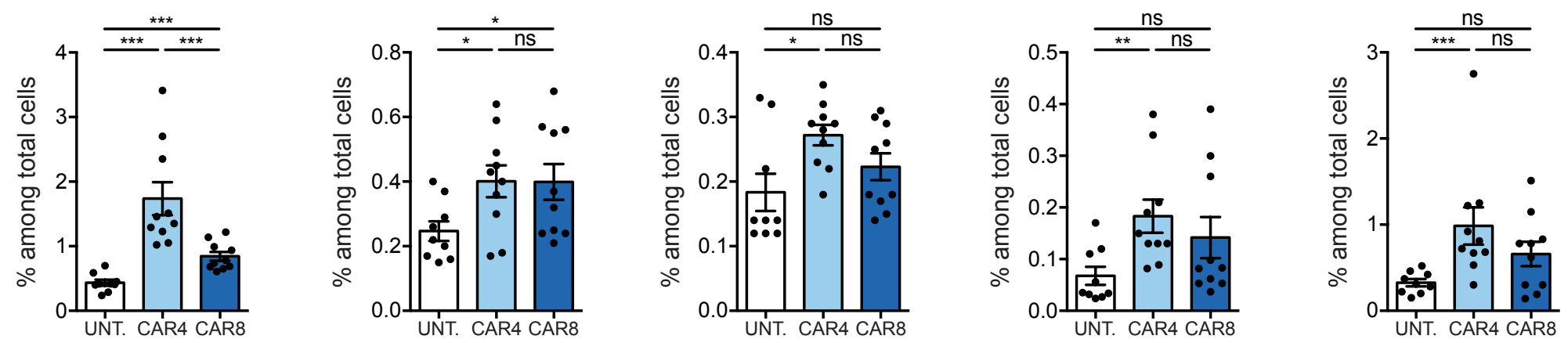

B
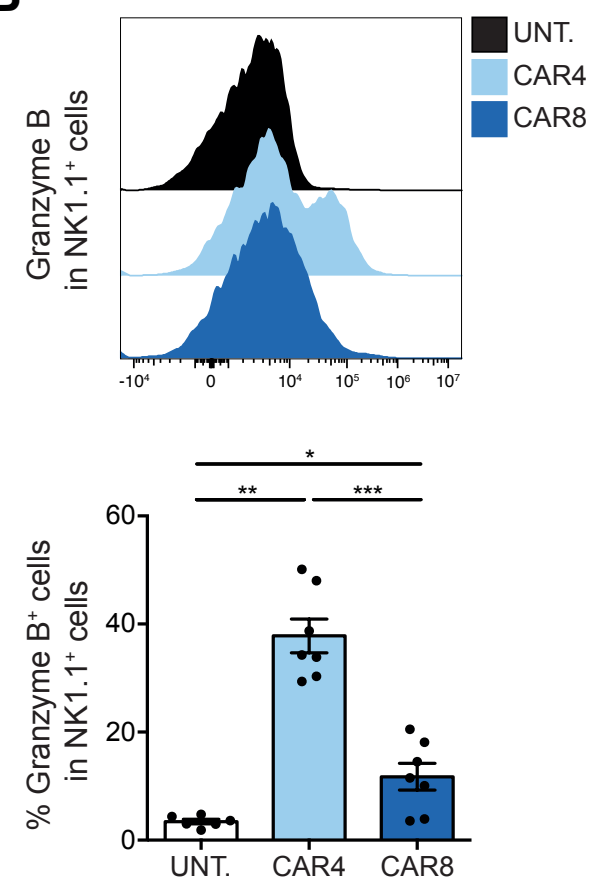

C
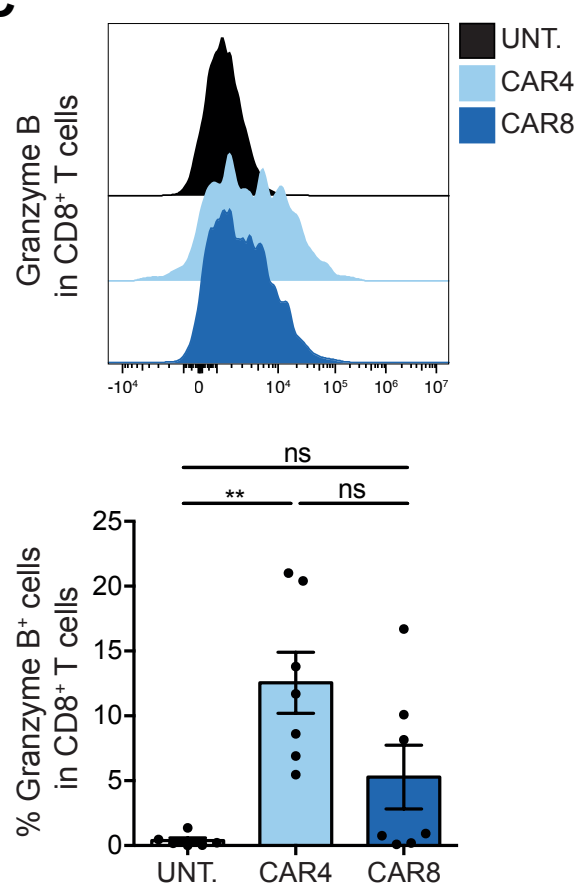

Blood

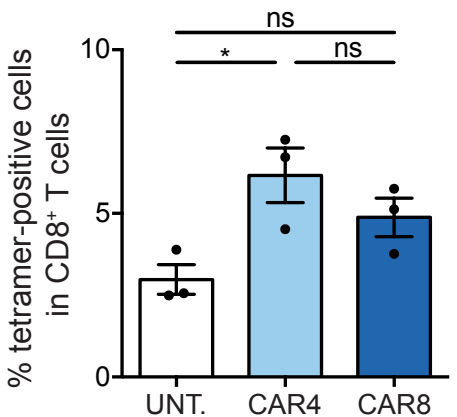

UNT. CAR4 CAR8
D
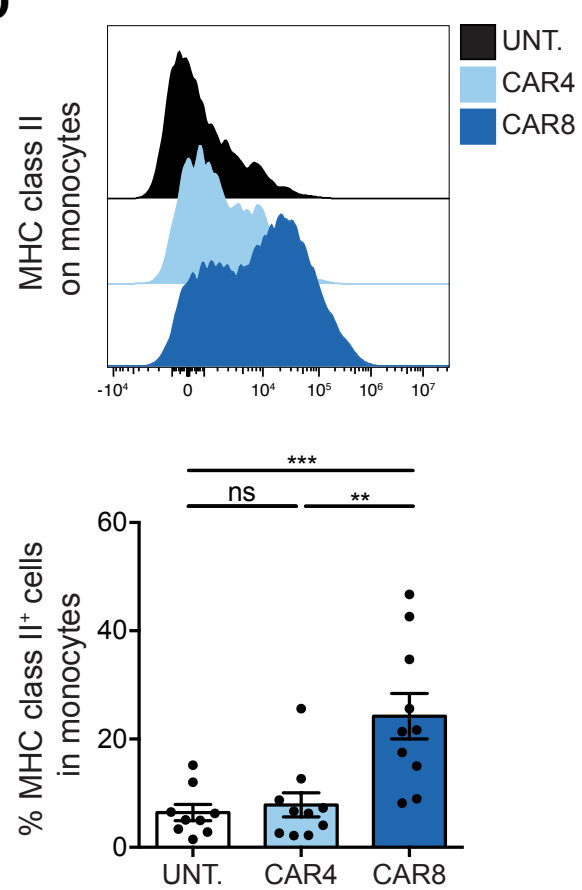

E

Bone marrow

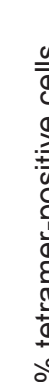

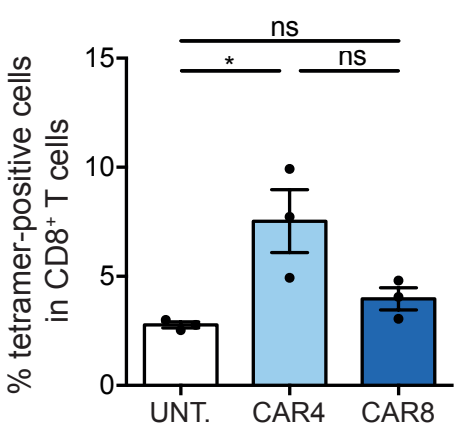


A crosstalk between CAR $T$ cell subsets and the tumor microenvironment is essential for sustained cytotoxic activity

Morgane Boulch, Marine Cazaux, Yann Loe-Mie, Ronan Thibaut, Béatrice Corre, Fabrice Lemaître, Capucine L. Grandjean, Zacarias Garcia and Philippe Bousso

Supplementary material 
A

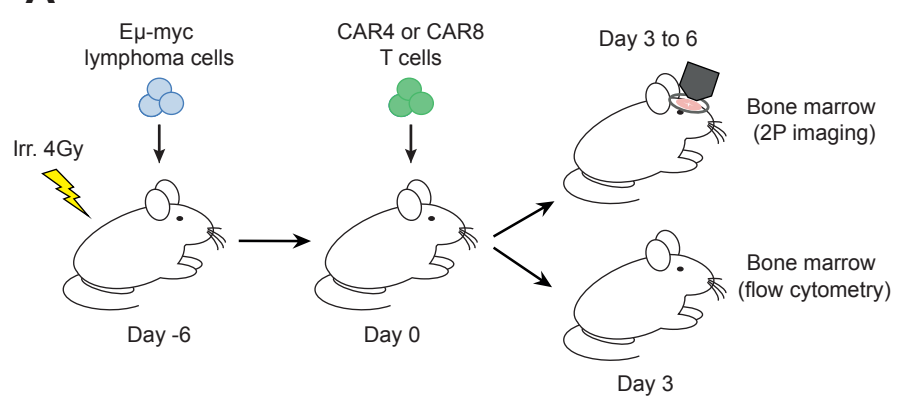

B

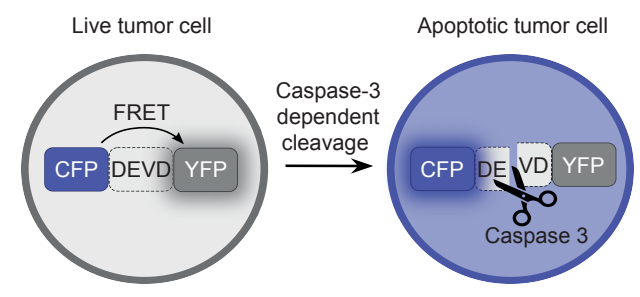

Figure S1. Assessing the cytotoxic potential of anti-CD19 CAR4 and CAR8 T cells in vivo using a genetically encoded reporter for apoptosis. (A) Experimental set up. B cell lymphoma was established by i.v. injection of $0.5 \times 10^{6} \mathrm{E} \mu$-myc cells in C57BL/6 mice after sublethal irradiation (4 Gy). Six days later, mice were injected i.v. with 10-20x10 ${ }^{6}$ CAR4 or CAR8 T cells. Bone marrow two-photon (2P) imaging was performed 3 to 6 days after T cell transfer. Bone marrow was analyzed by flow cytometry 3 days after $\mathrm{T}$ cell transfer. (B) Schematic of the FRET-based caspase-3 reporter used in E $\mu$-myc-DEVD malignant B cells to visualize apoptosis in real-time. CFP and YFP are linked by the target peptide DEVD, which is cleaved upon caspase-3 activation, resulting in loss of FRET in apoptotic cells. 

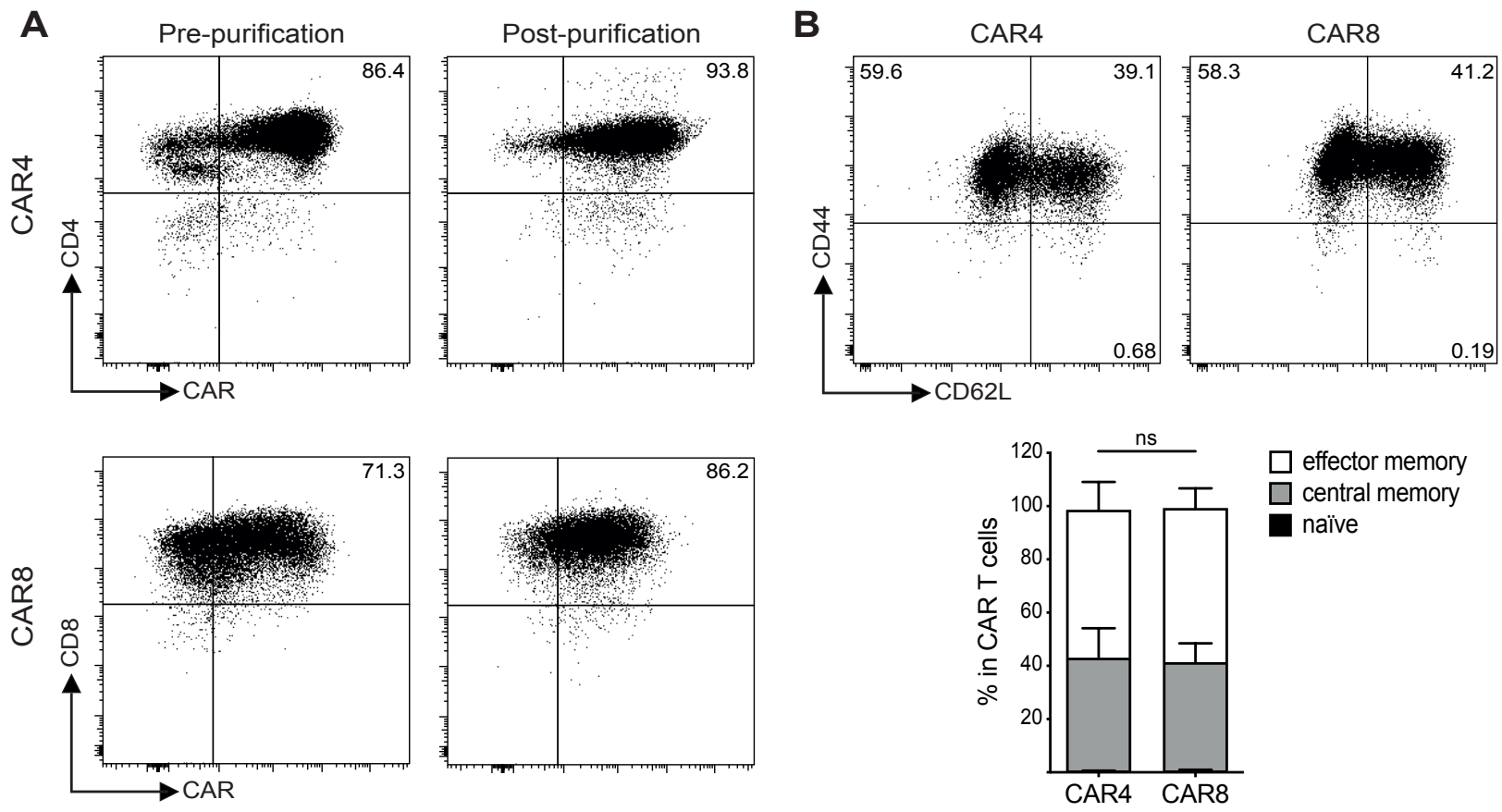

C
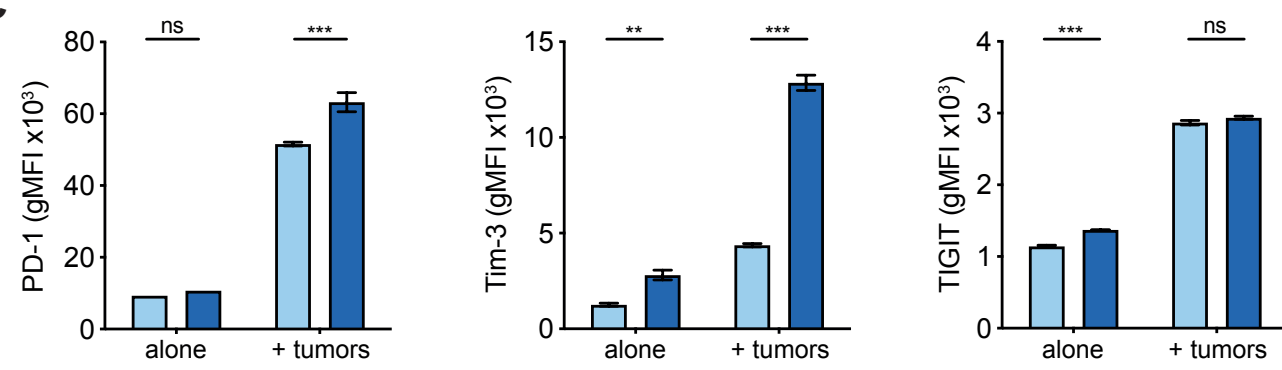

$\square$ CAR4

$\square$ CAR8

D

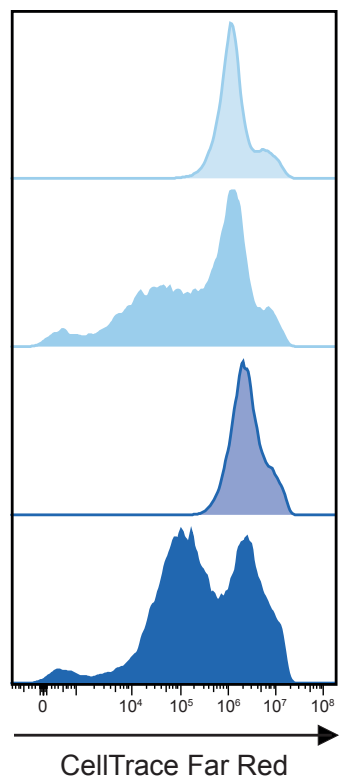

E

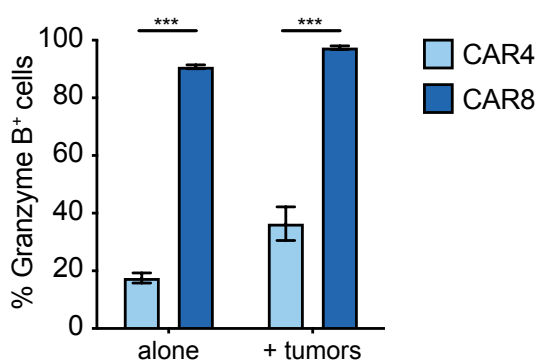

F

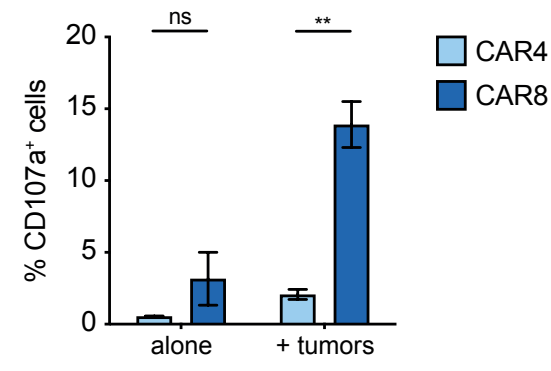


Figure S2. In vitro phenotyping of CAR4 and CAR8 T cells prior to adoptive cell transfer. (A) CAR expression by $\mathrm{CD} 4^{+}$and $\mathrm{CD} 8^{+} \mathrm{T}$ cells pre- and post-positive purification for hCD34 (representative of $>7$ independent experiments). (B) Percentage of effector memory $\left(\mathrm{CD} 44^{+} \mathrm{CD}^{-} \mathrm{L}^{-}\right)$, central memory $\left(\mathrm{CD} 44^{+} \mathrm{CD} \mathrm{L}^{+}\right)$and naïve $\mathrm{T}$ cells $\left(\mathrm{CD} 44^{-}\right.$ $\mathrm{CD}_{2} \mathrm{~L}^{+}$) in CAR4 and CAR8 T cells (pooled from 5 independent experiments). (C) Surface expression of PD-1 (left), Tim-3 (middle) and TIGIT (right) by CAR4 and CAR8 T cells cocultured (or not) with E $\mu$-myc-DEVD target cells at 1:1 effector-to-target ratio for 24 hours. gMFI, geometric mean fluorescence intensity. (D) Proliferation of CellTrace Far Redlabeled CAR4 and CAR8 T cells upon coculture with E $\mu$-myc-DEVD target cells for 72 hours at 1:1 effector-to-target ratio (representative of 2 independent experiments). (E) Expression of intracellular granzyme B content in CAR4 and CAR8 T cells alone or upon coculture with E $\mu$-myc-DEVD target cells at 1:1 effector-to-target ratio for 24 hours (pooled from 2 independent experiments). (F) Surface CD107a expression by CAR4 and CAR8 T cells cocultured (or not) with E $\mu$-myc-DEVD target cells at 1:1 effector-to-target ratio for 4 hours. (B-C and E-F) Two-way analysis of variance (ANOVA) was used for statistical analysis. ***, $\mathrm{p}<0.001 ; * *, \mathrm{p}<0.01 ; \mathrm{ns}$, not significant. 

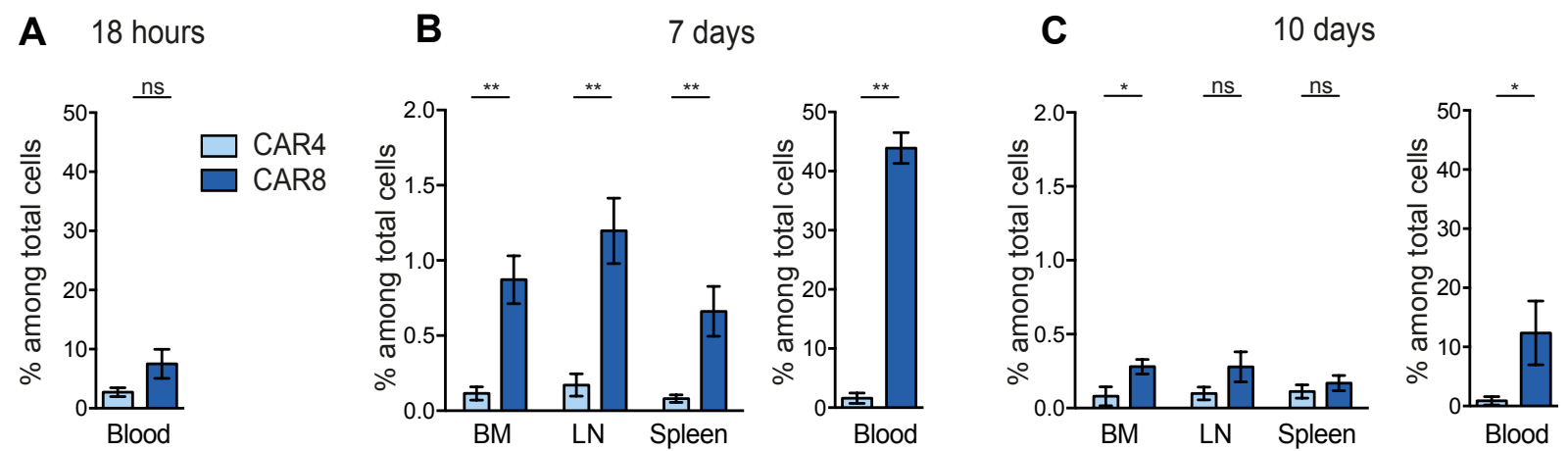

Figure S3. Kinetics of CAR $T$ cell accumulation in blood and lymphoid organs. E $\mu$ myc B cell lymphoma was established by i.v. injection of $0.5 \times 10^{6}$ E $\mu$-myc-DEVD cells in C57BL/6 mice after sublethal irradiation (4 Gy). Six days later, mice were injected i.v. with 10x $10^{6}$ CAR4 or CAR8 $\mathrm{T}$ cells. CAR $\mathrm{T}$ cells were detected as $\mathrm{hCD} 34^{+}$cells by flow cytometry in blood, bone marrow (BM), lymph nodes (LN) and spleen at different time points following CAR T cell injection, including (A) 18 hours, (B) 7 days and (C) 10 days. Of note, at 18 hours, CAR T cells were only detectable in the blood. Data are pooled from two independent experiments. Two-tailed Mann-Whitney U-test was used for statistical analysis. **, $\mathrm{p}<0.01 ; *, \mathrm{p}<0.05 ; \mathrm{ns}$, not significant. 


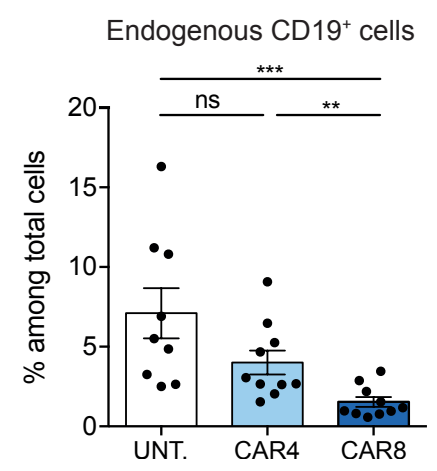

Figure S4. CAR4 $T$ cells are poorly effective at eliminating endogenous B cells in vivo. (A) C57BL/6 mice were injected i.v. with $0.5 \times 10^{6} \mathrm{E} \mu$-myc lymphoma cells after their sublethal irradiation (4 Gy). Six days later, mice were injected i.v. with $20 \times 10^{6}$ anti-CD19 CAR4 or CAR8 $\mathrm{T}$ cells or left untreated. After 3 days, bone marrow was harvested and analyzed by flow cytometry. Bar chart showing the percentage of endogenous CD19 $9^{+}$B cells remaining in the bone marrow. Representative of three independent experiments. Each dot represents one mouse. Two-tailed Mann-Whitney U-test was used for statistical analysis. ***, $\mathrm{p}<0.001 ; * *, \mathrm{p}<0.01 ; \mathrm{ns}$, not significant. 
A

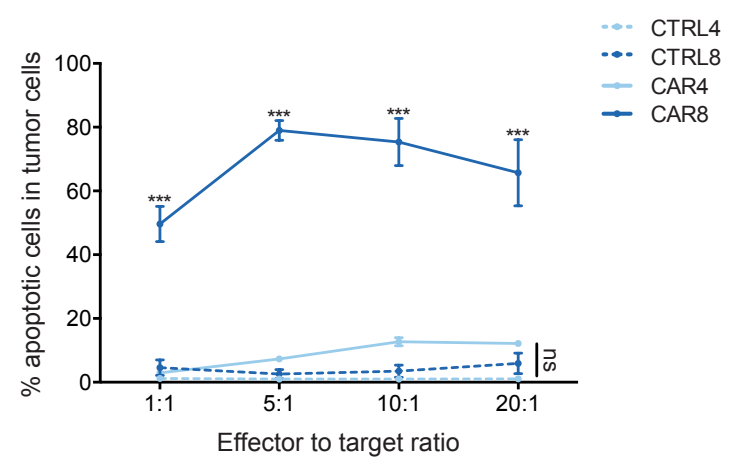

B

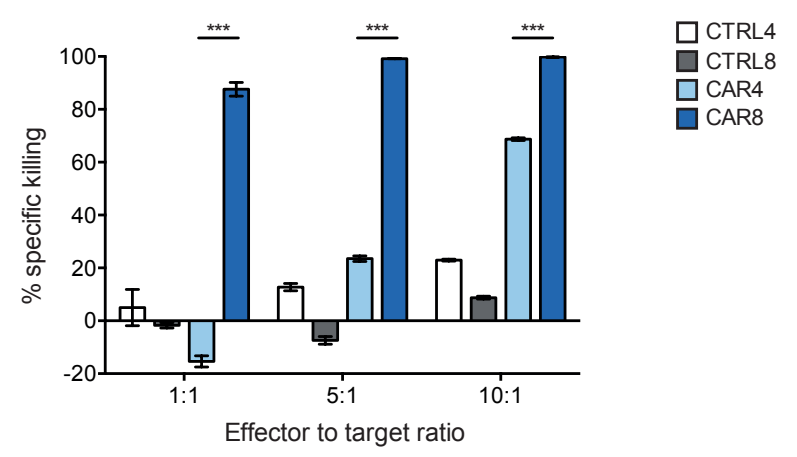

Figure S5. CAR4 $\mathrm{T}$ cells are poorly effective at inducing tumor cell killing in vitro. In vitro quantification of CAR4 and CAR8 T cell cytotoxic activity. Anti-CD19 CAR T cells, untransduced control CD4 ${ }^{+} \mathrm{T}$ cells (CTRL4) and untransduced control CD8 ${ }^{+} \mathrm{T}$ cells (CTRL8) were cocultured for 6 hours with E $\mu$-myc-DEVD CD19 ${ }^{+}$target cells at various effector-totarget (E:T) ratios. (A) Summary graph showing the percentage of apoptosis within tumor cells at the indicated E:T ratios. Data are pooled from four independent experiments. Twoway analysis of variance (ANOVA) was used for statistical analysis. ***, p $<0.001$; ns, not significant. (B) The percentage of specific target cell killing by CAR4 or CAR8 T cells at various E:T ratios is shown. Two-way analysis of variance (ANOVA) was used for statistical analysis. ${ }^{* * *}, \mathrm{p}<0.001$. 
A

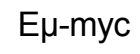

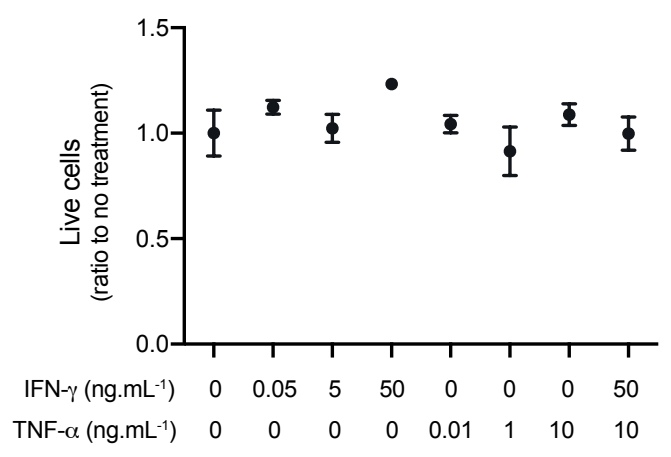

C

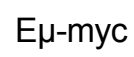

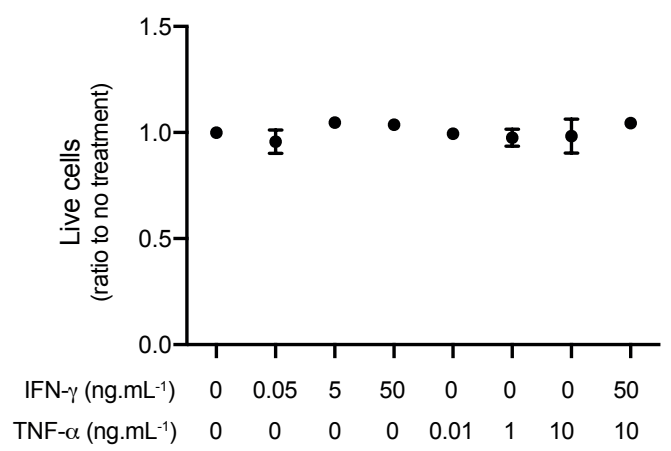

E

Eu-myc

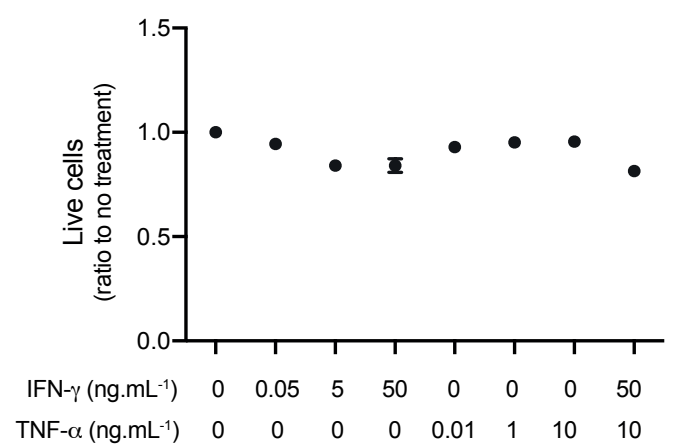

B

B16.F10

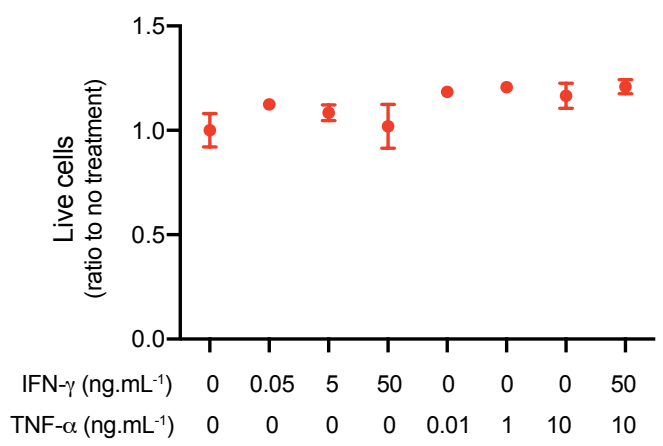

D

B16.F10

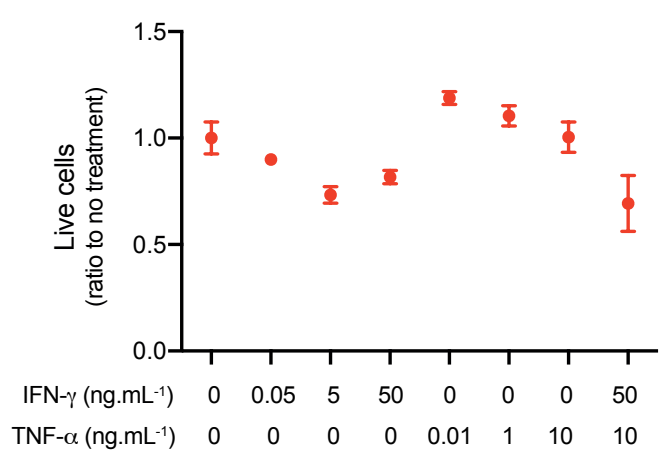

$\mathbf{F}$

B16.F10

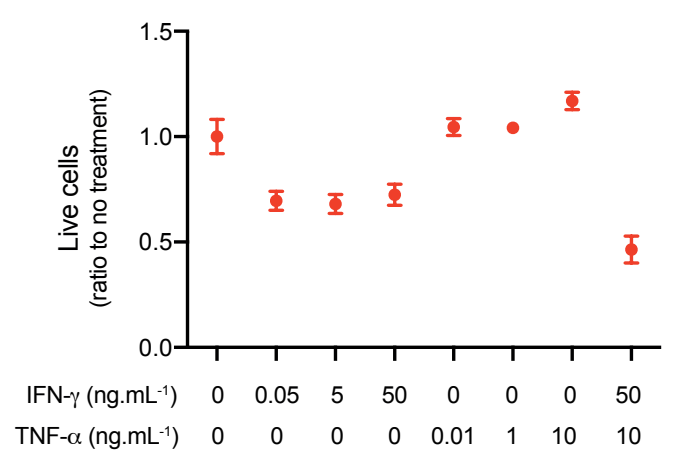

Figure S6. Tumor sensitivity to cytokine-induced cell death. Effect of IFN- $\gamma$ and TNF- $\alpha$

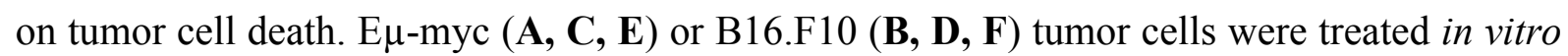


with the indicated concentrations of IFN- $\gamma$ and/or TNF- $\alpha$ for 4h (A-B), 24h (C-D) or 48h (EF). Viable remaining tumor cells were counted using flow cytometry. 


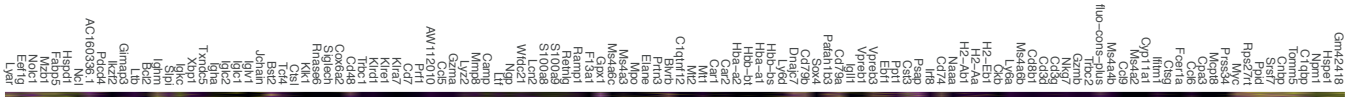
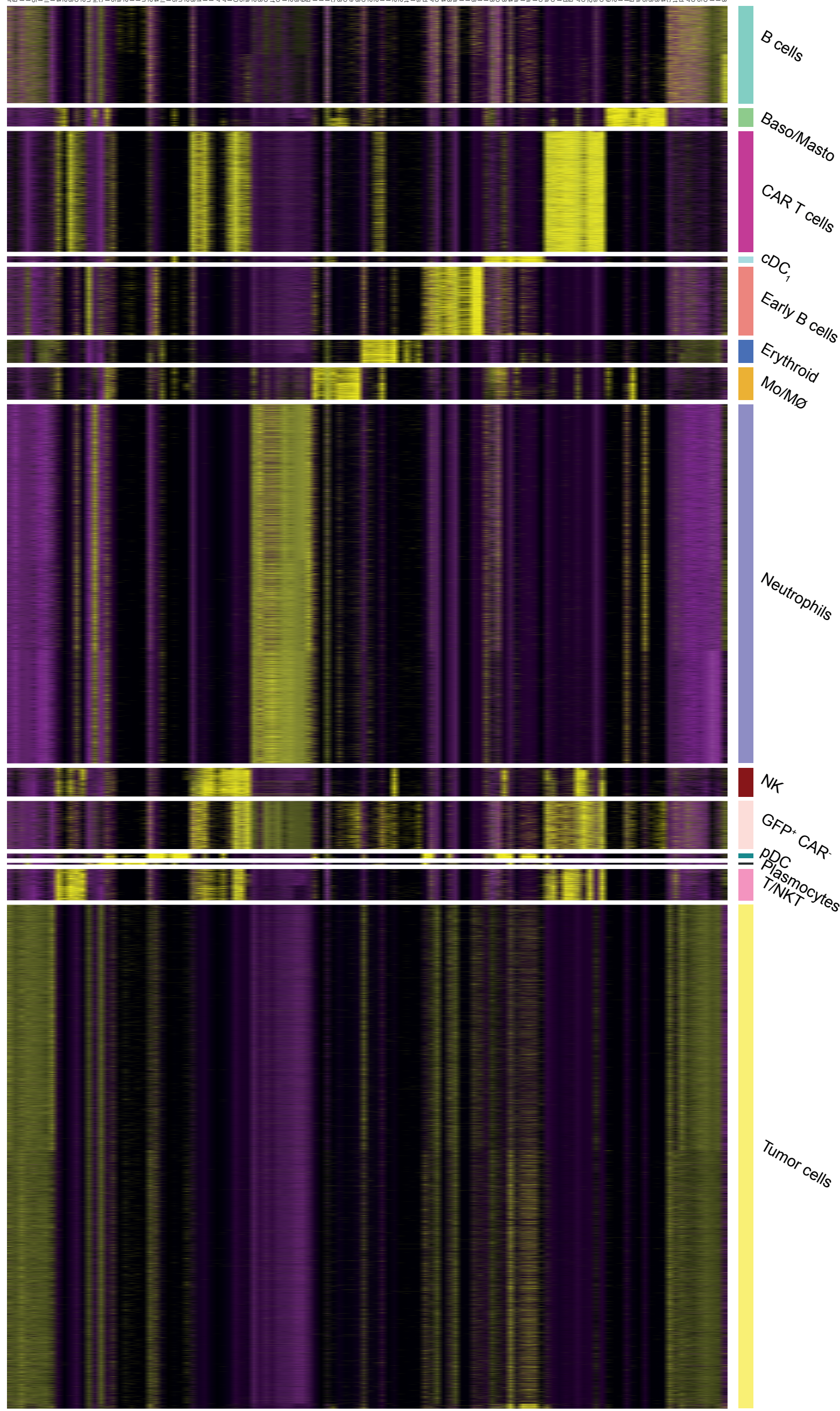

$v_{k}$
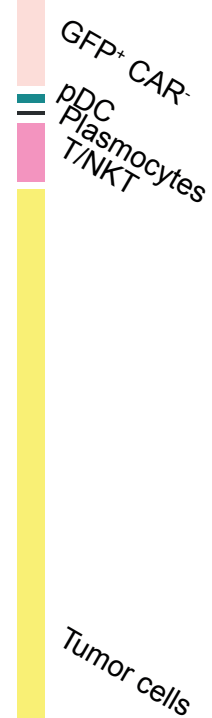
Figure S7. Identification of tumor infiltrating immune cells by single-cell RNA sequencing. Clustering of 30,041 immune cells from untreated, CAR4 T cell-treated and CAR8 T cell-treated mice, featuring 118 marker genes identified by the Cellranger pipeline. The heatmap presents the most differentially expressed genes used for identification of the clusters depicted in Figure 2A. Color bars above the heatmap indicate cluster identity. Gene expression is scaled from low-violet to high-yellow. 
A
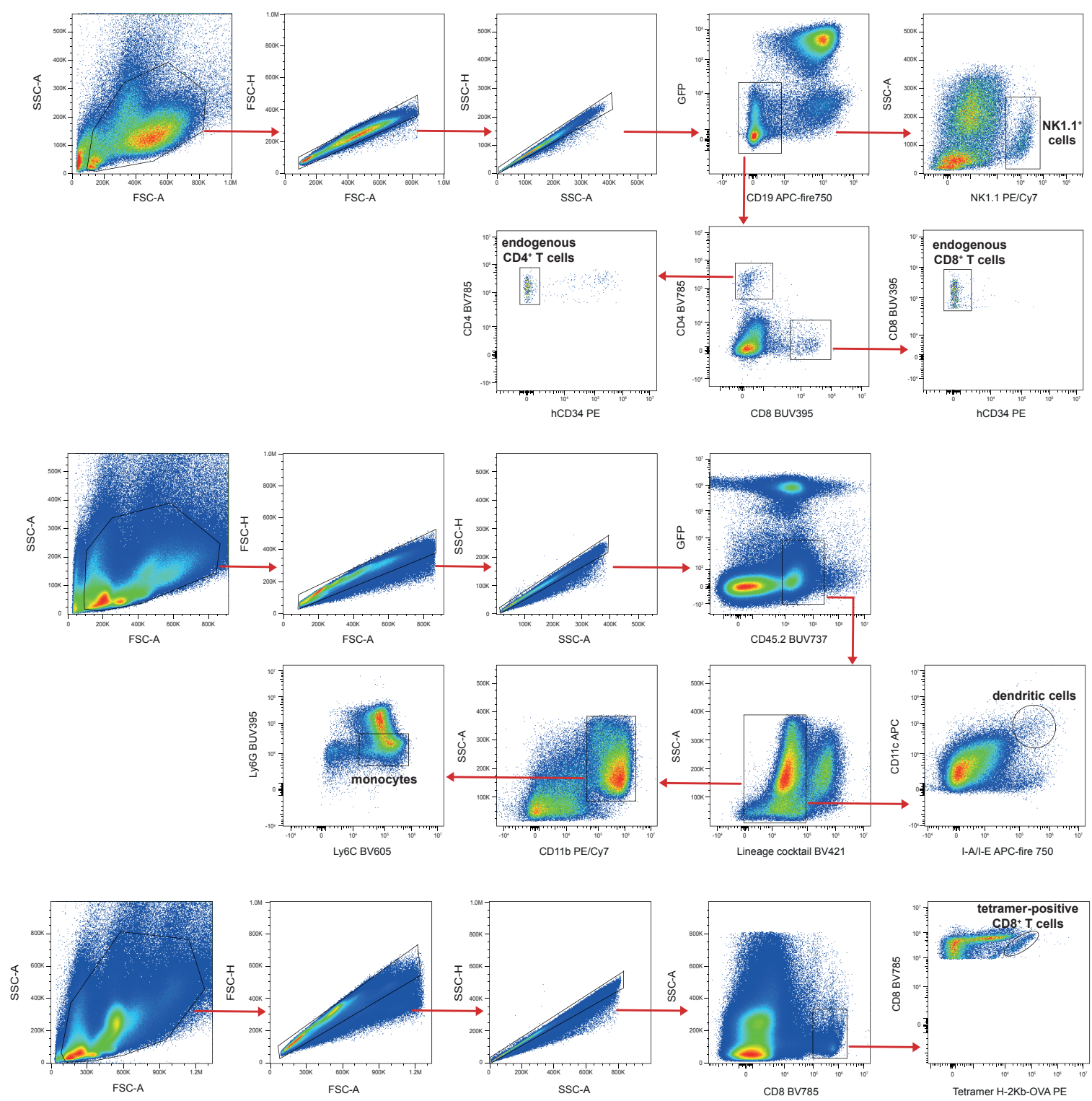

B

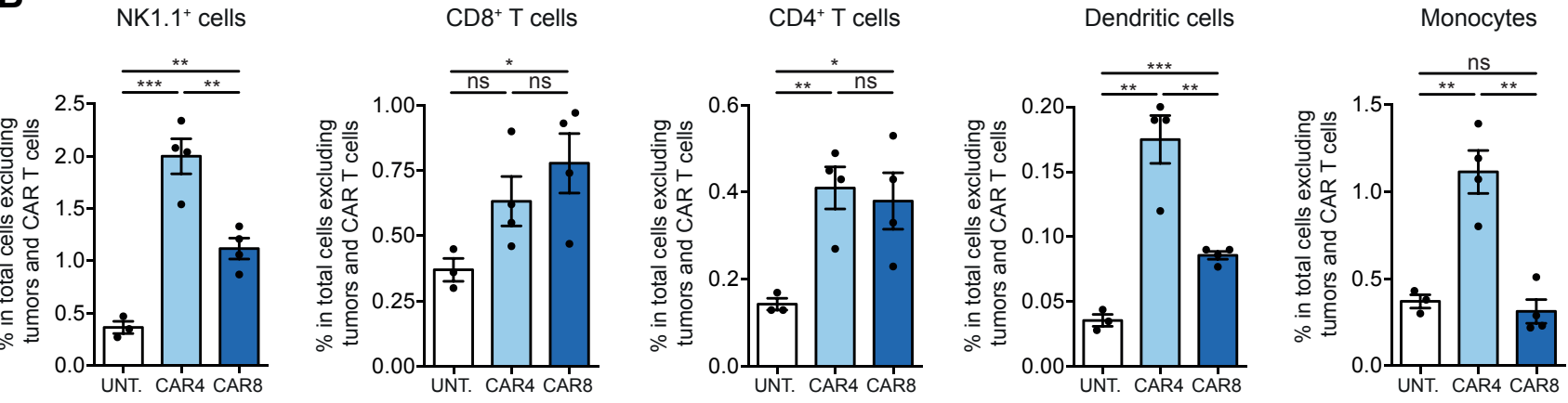

C

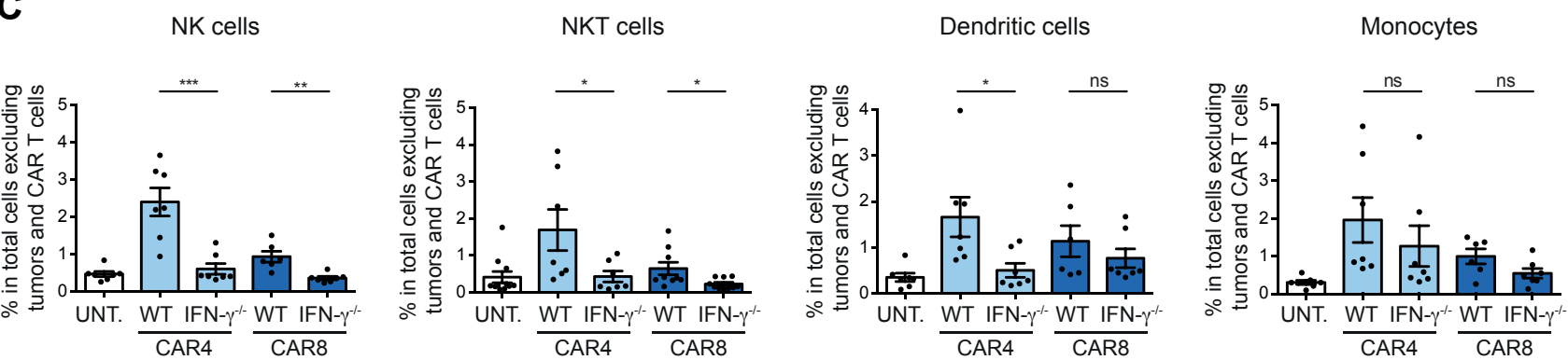


Figure S8. CAR T cells promote host immune cell recruitment at the tumor site. B cell lymphoma was established by i.v. injection of $0.5 \times 10^{6}$ E $\mu$-myc-DEVD cells in C57BL/6 mice after sublethal irradiation (4 Gy). (A) Gating strategies for flow cytometry identification of NK $1.1^{+}$cells, endogenous $\mathrm{CD}^{+} \mathrm{T}$ cells, endogenous $\mathrm{CD}^{+} \mathrm{T}$ cells, dendritic cells, monocytes and OVA-specific $\mathrm{CD}^{+} \mathrm{T}$ cells present in the bone marrow of tumor-bearing mice. Lineage cocktail comprises BV421 conjugated anti-mouse antibodies against NK1.1, CD4, TCR $\beta$ chain, CD19, TER-119, CD34 and c-kit. (B) Six days later, mice were injected i.v. with $20 \times 10^{6}$ CAR4 or CAR8 T cells or left untreated. After 3 days, the bone marrow was harvested and analyzed by flow cytometry. Percentage of NK $1.1^{+}$cells, $\mathrm{CD} 8^{+} \mathrm{T}$ cells, CD4 ${ }^{+} \mathrm{T}$ cells, dendritic cells $\left(\mathrm{CD} 11 \mathrm{c}^{+} \mathrm{I}-\mathrm{A} / \mathrm{I}-\mathrm{E}^{+}\right)$and monocytes $\left(\mathrm{CD} 11 \mathrm{~b}^{+} \mathrm{Ly}_{6 \mathrm{G}}^{-} \mathrm{Ly}_{6 \mathrm{C}^{+}}\right)$ among total cells after gating out tumors and CAR $\mathrm{T}$ cells. Representative of three independent experiments. Each dot represents one mouse. Unpaired $\mathrm{t}$ test was used for statistical analysis. ${ }^{* *}, \mathrm{p}<0.001 ; * *, \mathrm{p}<0.01 ; *, \mathrm{p}<0.05$; ns, not significant. (C) Six days later, mice were injected i.v. with $10 \times 10^{6} \mathrm{WT}$ or IFN- $\gamma^{-/-}$CAR4 or CAR8 T cells or left untreated. After 3 days, the bone marrow was harvested and analyzed by flow cytometry. Percentage of NK cells $\left(\mathrm{NK} 1.1^{+} \mathrm{CD}^{-}\right)$, NKT cells $\left(\mathrm{NK} 1.1^{+} \mathrm{CD}^{+}\right)$, dendritic cells $\left(\mathrm{CD} 11 \mathrm{c}^{+} \mathrm{I}-\mathrm{A} / \mathrm{I}-\mathrm{E}^{+}\right)$and monocytes $\left(\mathrm{CD} 11 \mathrm{~b}^{+}\right.$Ly6G $^{-}$Ly6C $\left.\mathrm{C}^{+}\right)$among total cells after gating out tumors and CAR T cells. Data are pooled from two independent experiments. Each dot represents one mouse. Unpaired $t$ test was used for statistical analysis. **, $p<0.01 ; *, p<0.05 ;$ ns, not significant. 


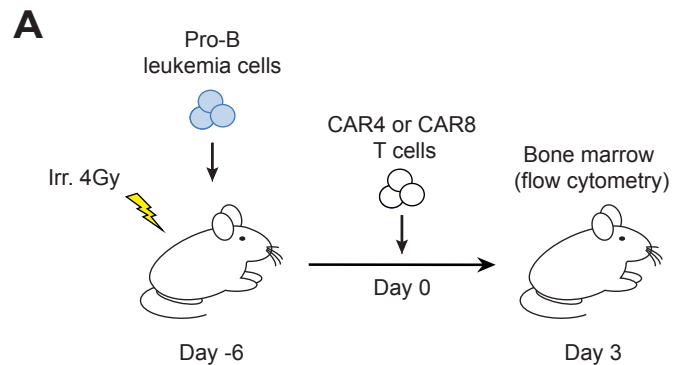

B
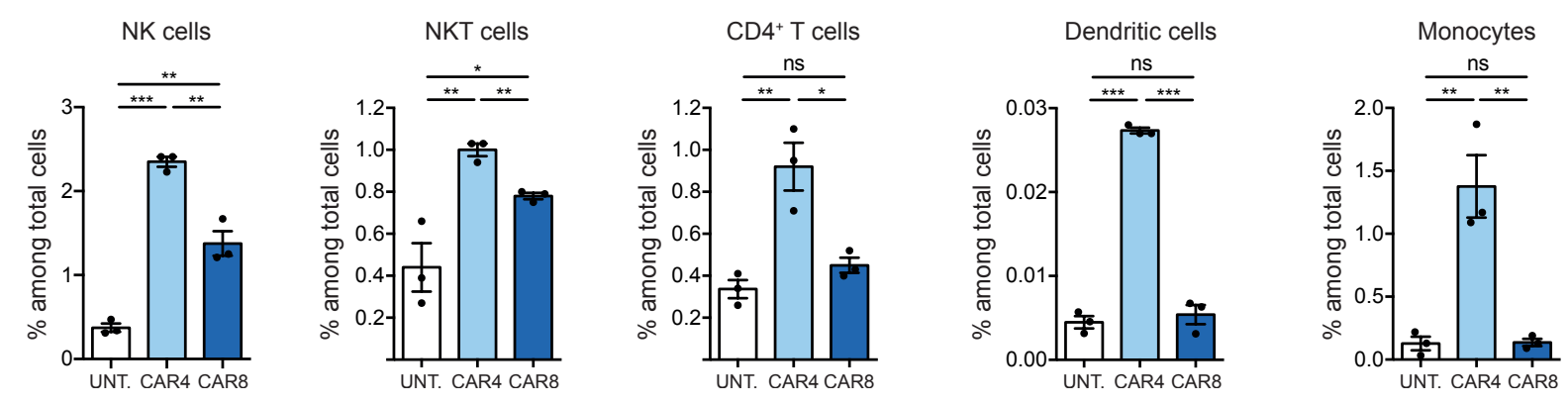

Figure S9. CAR $T$ cell therapy induces a broad mobilization of host immunity in a model of pro-B leukemia cells. (A) Experimental set up. C57BL/6 mice were injected i.v. with $0.5 \times 10^{6}$ pro-B leukemia cells after their sublethal irradiation (4 Gy). Six days later, mice were injected i.v. with $10 \times 10^{6}$ CAR4 or CAR8 T cells or left untreated. After 3 days, the bone marrow was harvested and analyzed by flow cytometry. (B) Percentage of NK cells $\left(\mathrm{NK} 1.1^{+} \mathrm{CD}^{-}\right)$, NKT cells $\left(\mathrm{NK} 1.1^{+} \mathrm{CD}^{+}\right), \mathrm{CD}^{+} \mathrm{T}$ cells $\left(\mathrm{CD} 19^{-} \mathrm{CD}^{+}\right)$, dendritic cells $\left(\mathrm{CD} 11 \mathrm{c}^{+} \mathrm{I}-\mathrm{A} / \mathrm{I}-\mathrm{E}^{+}\right)$and monocytes $\left(\mathrm{CD} 11 \mathrm{~b}^{+} \mathrm{Ly}_{6 \mathrm{G}^{-}} \mathrm{Ly}_{6 \mathrm{C}^{+}}\right)$recovered. Representative of two independent experiments. Each dot represents one mouse. Unpaired t test was used for statistical analysis. ${ }^{* * *}, \mathrm{p}<0.001 ; * *, \mathrm{p}<0.01 ; *, \mathrm{p}<0.05$; ns, not significant. 
A

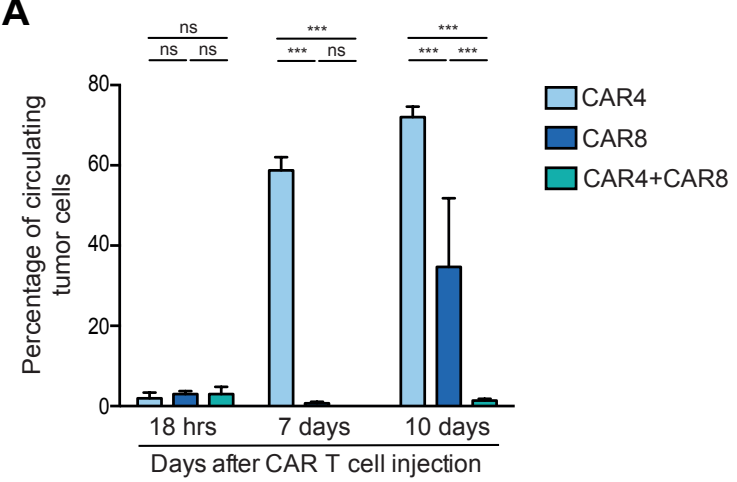

B

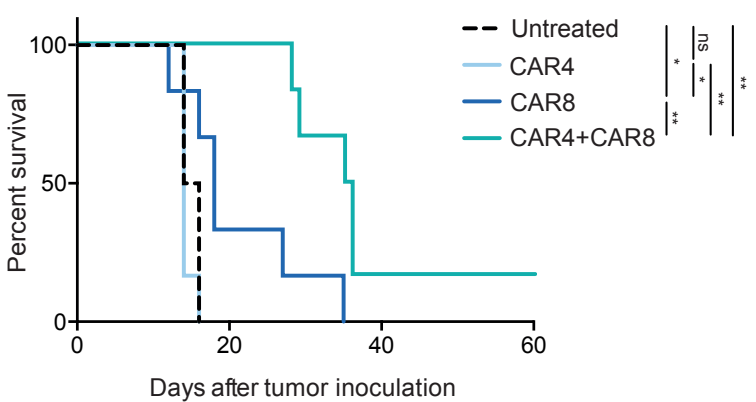

Figure S10. Combining CAR4 and CAR8 $T$ cells improves anti-tumor activity. E $\mu$ myc B cell lymphoma was established by i.v. injection of $0.5 \times 10^{6} \mathrm{E} \mu$-myc-DEVD cells in C57BL/6 mice after sublethal irradiation (4 Gy). Six days later, mice were injected i.v. with $10 \times 10^{6}$ CAR4 T cells or CAR8 T cells or a combination of $10 \times 10^{6}$ CAR4 and $10 \times 10^{6}$ CAR8 T cells. (A) Circulating tumor load was assessed by flow cytometry at different time points following CAR $\mathrm{T}$ cell injection. Two-way analysis of variance (ANOVA) was used for statistical analysis. ${ }^{* * *}, \mathrm{p}<0.001$; ns, not significant. (B) Mouse survival was significantly extended by the combination of CAR4 and CAR8 T cells. Log-rank test was used for statistical analysis. $*^{* *}, \mathrm{p}<0.001 ; * *, \mathrm{p}<0.01 ; *, \mathrm{p}<0.05$; ns, not significant. Data are representative of two independent experiments $(n=6$ mice per group). 
A

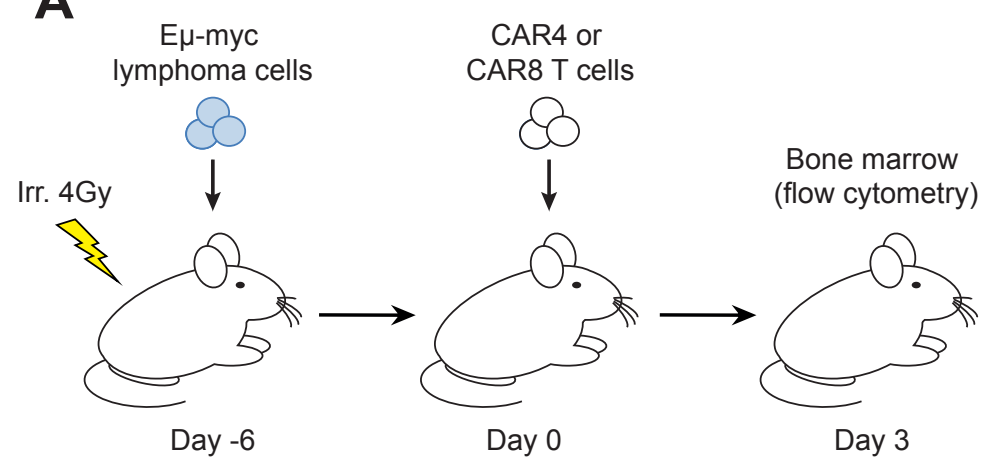

B

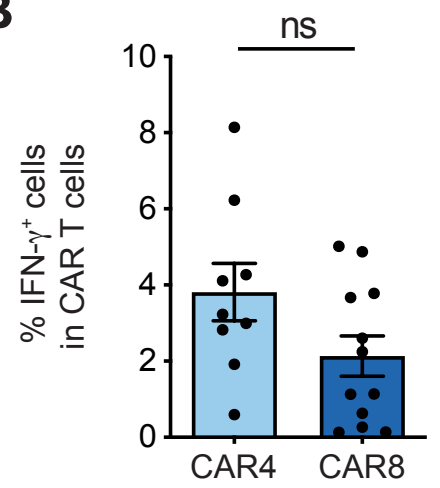

Figure S11. WT CAR T cells produce IFN- $\gamma$ at the tumor site in vivo. (A) Experimental set up. C57BL/6 mice were injected i.v. with $0.5 \times 10^{6}$ E $\mu$-myc lymphoma cells after their sublethal irradiation (4 Gy). Six days later, mice were injected i.v. with 10x10 ${ }^{6}$ WT CAR4 or CAR8 T cells. After 3 days, bone marrow was harvested and analyzed by flow cytometry. (B) Percentage of CAR T cells producing IFN- $\gamma$ ex vivo (in the absence of restimulation). Data are pooled from four independent experiments. Each dot represents one mouse. Two-tailed Mann-Whitney U-test was used for statistical analysis. **, $\mathrm{p}<0.01$. 
A

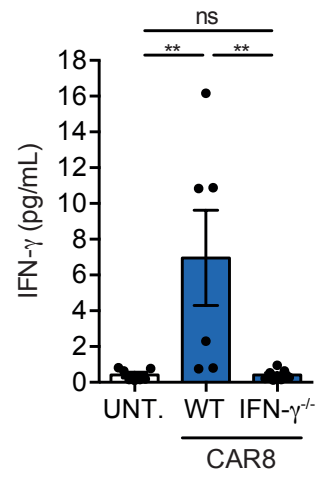

C

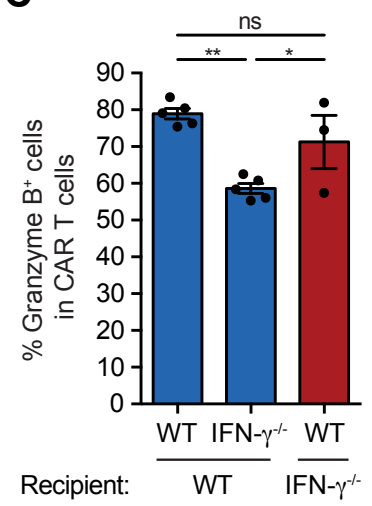

D

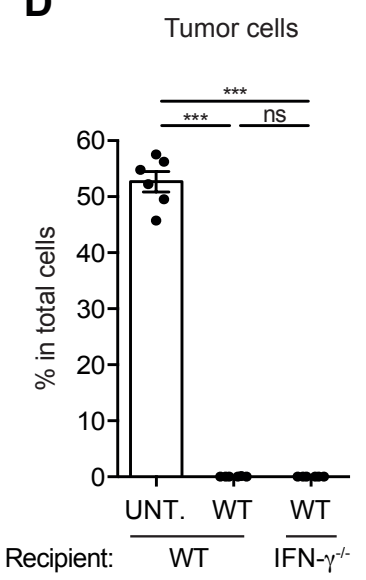

B

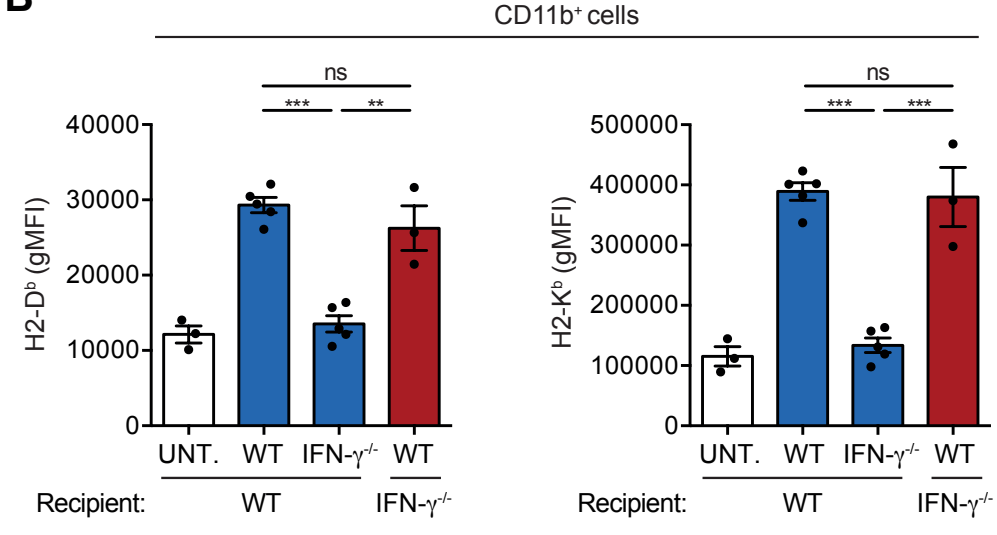

Tumor cells

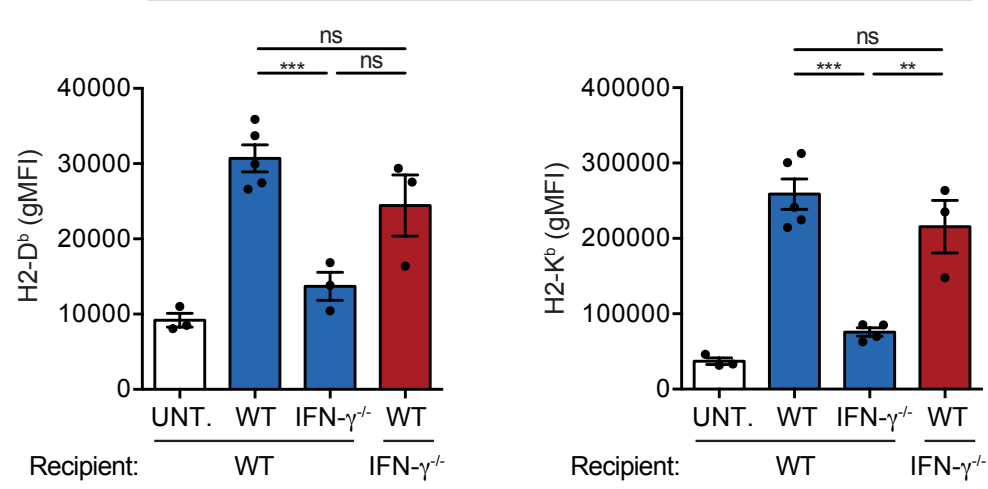

Endogenous CD19+ cells

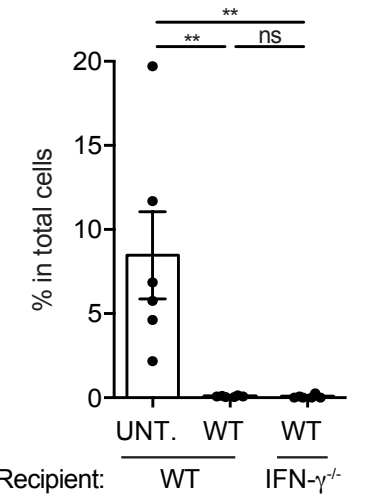

$\mathbf{E}$

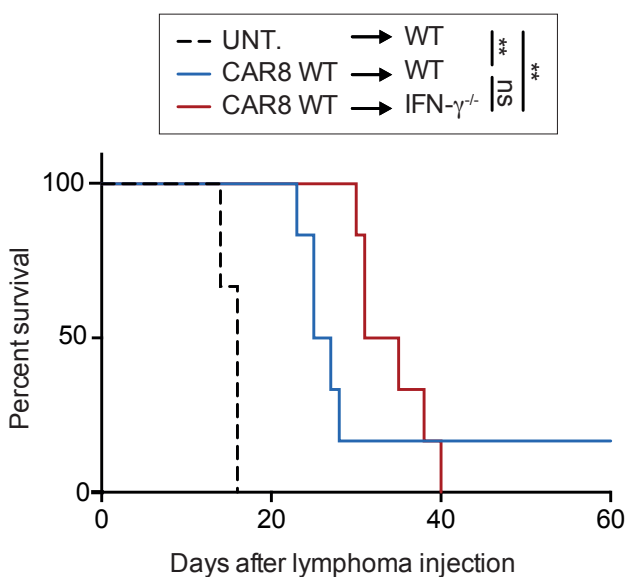

Figure S12. CAR T cell-derived IFN- $\gamma$ is sufficient to promote anti-tumor activity. B cell lymphoma was established by i.v. injection of $0.5 \times 10^{6}$ E $\mu$-myc-DEVD cells in C57BL/6 or IFN- $\gamma$-deficient mice after sublethal irradiation (4 Gy). Six days later, mice were injected i.v. 
with $10 \times 10^{6}$ WT or IFN- $\gamma^{-/-}$CAR8 T cells or left untreated. (A) CAR T cells are the major source of IFN- $\gamma$. Sera were collected three days after CAR T cell transfer, and IFN- $\gamma$ production was measured by multiplex assay. Data are pooled from two independent experiments ( $\mathrm{n}=3-4$ mice per group). Each dot represents one mouse. Two-tailed MannWhitney U-test was used for statistical analysis. **, $\mathrm{p}<0.01$; ns, not significant. (B) CAR T cell-derived IFN- $\gamma$ increases MHC class I levels in tumor and tumor-infiltrating immune cells. Lymphoma-bearing WT or IFN- $\gamma^{-/-}$mice were treated with $10 \times 10^{6} \mathrm{WT}$ or IFN- $\gamma$-deficient CAR8 T cells. Surface expression of $\mathrm{H} 2-\mathrm{D}^{\mathrm{b}}$ (left) and $\mathrm{H} 2-\mathrm{K}^{\mathrm{b}}$ (right) was assessed on CD11 $\mathrm{b}^{+}$ myeloid cells (top) and tumor cells (bottom) on day 3. gMFI, geometric mean fluorescence intensity. Representative of two independent experiments. Each dot represents one mouse. Unpaired t test was used for statistical analysis. ${ }^{* * *}, \mathrm{p}<0.001$; ${ }^{* *}, \mathrm{p}<0.01$; ns, not significant. (C) Intracellular granzyme B content in CAR8 $\mathrm{T}$ cells within the bone marrow on day 3. Representative of two independent experiments. Each dot represents one mouse. One-way analysis of variance (ANOVA) was used for statistical analysis. ${ }^{* *}, \mathrm{p}<0.01 ;{ }^{*}, \mathrm{p}<0.05$; ns, not significant. (D) Circulating E $\mu$-myc tumor cells and endogenous $\mathrm{CD} 19^{+}$cells were assessed in the blood by flow cytometry on day 7 following CAR T cell injection. Each dot represents one mouse. One-way analysis of variance (ANOVA) was used for statistical analysis. ***, $\mathrm{p}<0.001 ; * *, \mathrm{p}<0.01$; ns, not significant. (E) Host-derived IFN- $\gamma$ is not required for CAR T cell therapy ( $\mathrm{n}=6$ mice per group). Log-rank test was used for statistical analysis. ${ }^{* *}, \mathrm{p}<0.01$; ns, not significant. 

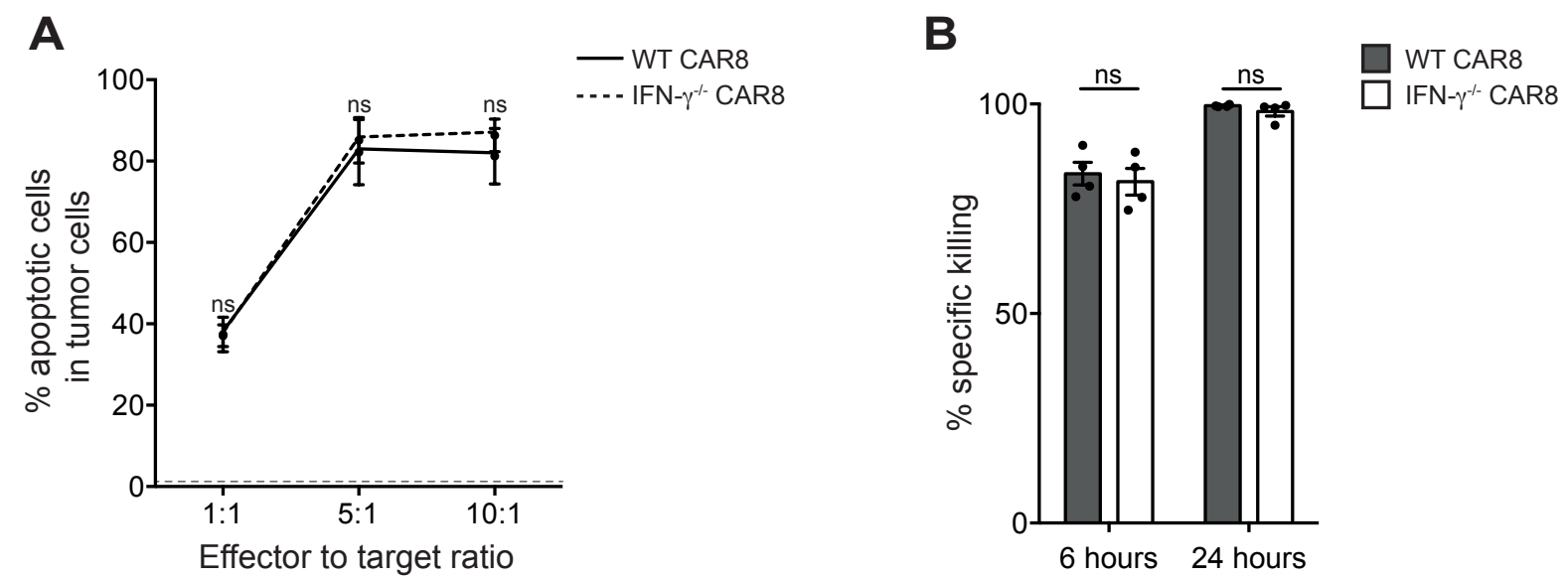

Figure S13. WT and IFN- $\gamma$-deficient CAR8 T cells exhibit similar killing activities prior to in vivo transfer. (A-B) In vitro quantification of WT and IFN- $\gamma$-deficient CAR8 T cell

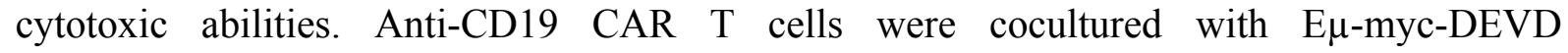
$\mathrm{CD} 19^{+}$target cells at various effector-to-target (E:T) ratios. Summary graphs showing (A) the percentage of apoptosis within tumor cells when cocultured for 2 hours with WT or IFN- $\gamma$ deficient CAR8 $\mathrm{T}$ cells at the indicated E:T ratios. The dotted gray line corresponds to the spontaneous apoptosis rate in tumor cells in the absence of effectors. (B) The percentage of specific target cell killing by WT or IFN- $\gamma$-deficient CAR8 T cells at 1:1 E:T ratio is shown for 6 or 24 hour-coculture. Data are pooled from two independent experiments. Two-way analysis of variance (ANOVA) was used for statistical analysis. ns, not significant. 
A

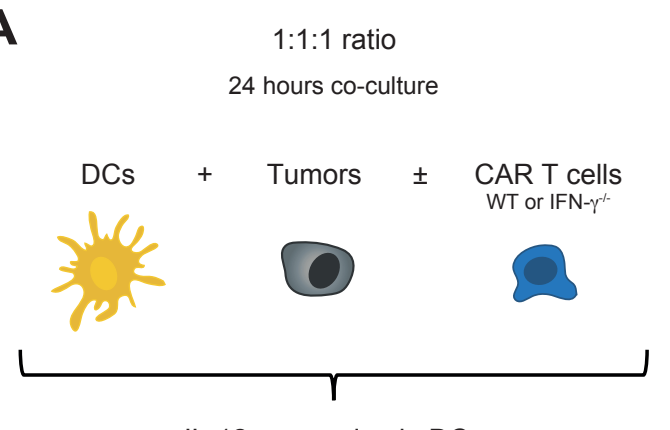

IL-12 expression in DCs
B

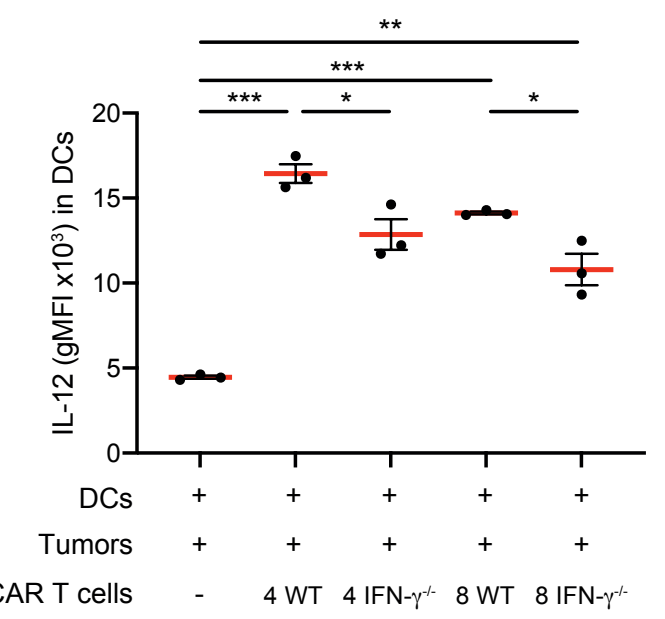

Figure S14. CAR T cell-derived IFN- $\gamma$ promotes IL-12 expression by DCs in vitro. (A) Experimental set up. Mutu DCs (a $\mathrm{CD}^{+}$DC cell line derived from CD11c:SV40LgTtransgenic mice) were cocultured with E $\mu$-myc-DEVD tumor cells and CAR T cells at 1:1:1 ratio. 24 hours later, intracellular IL-12 expression in DCs was assessed using flow cytometry. (B) Intracellular IL-12 expression in DCs. gMFI, geometric mean fluorescence intensity. Unpaired $\mathrm{t}$ test was used for statistical analysis. ***, $\mathrm{p}<0.001{ }^{*}, \mathrm{p}<0.05$. 


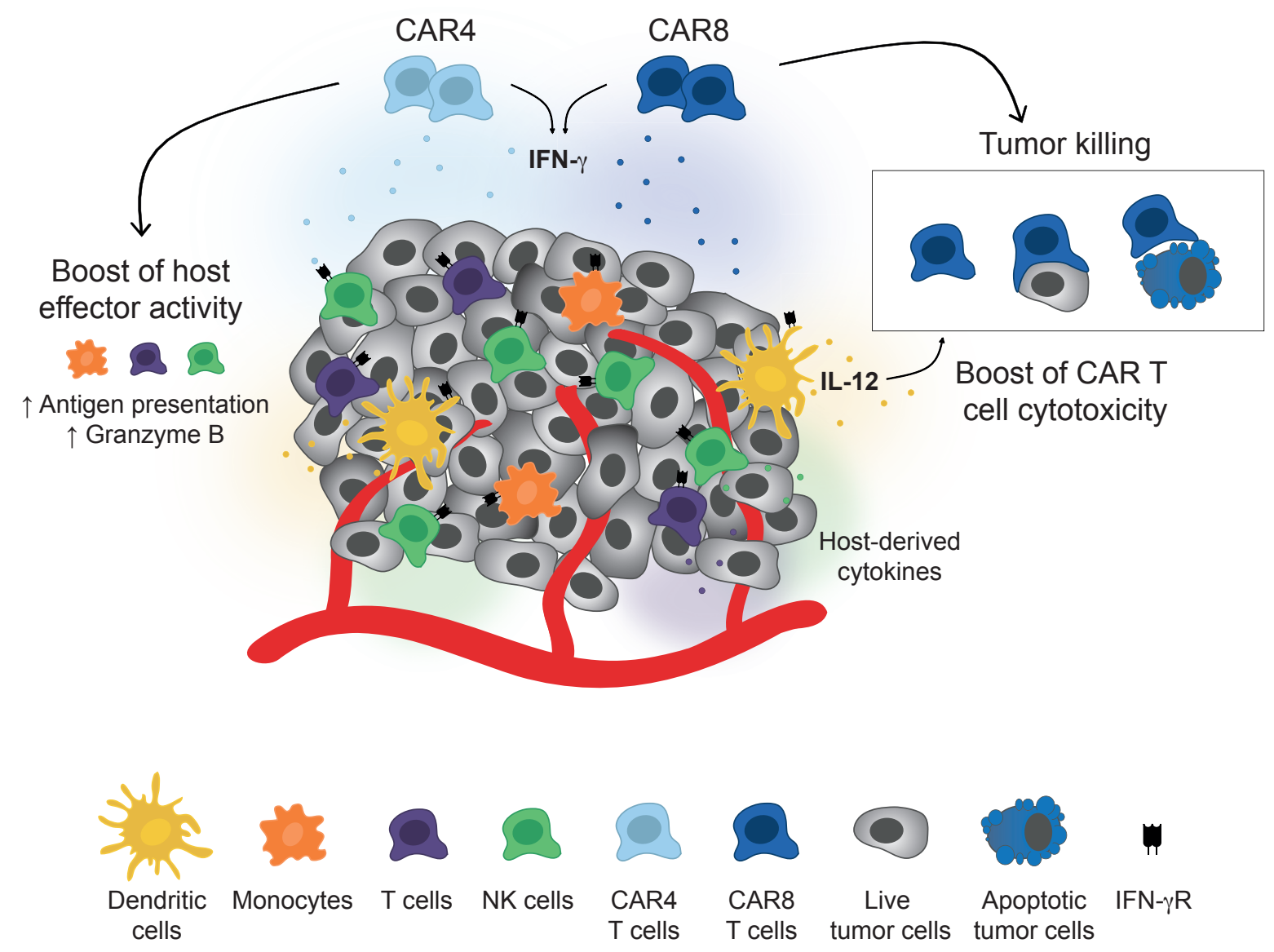

Figure S15. CAR T cell-mediated anti-tumor activity relies on cellular crosstalks within the tumor microenvironment. Graphical scheme illustrating the cellular crosstalks established by CAR4 T cells, CAR8 T cells and the tumor microenvironment promoting optimal anti-tumor activity. 


\section{Movie legends}

Movie S1. Both CAR4 and CAR8 $T$ cells infiltrate and patrol tumor-invaded bone marrow. C57BL/6 mice were sublethally irradiated and injected with E $\mu$-myc-DEVD tumor cells six days before treatment with $20 \times 10^{6}$ GFP-expressing CAR4 or CAR8 T cells. After 3 days, intravital imaging of the bone marrow was performed. As early as day 3, both CAR4 and CAR8 T cells can be found at the tumor site, infiltrating and surveying tumor cells. CAR $\mathrm{T}$ cells are shown in green, live tumor cells in white, and apoptotic tumor cells in blue. Scale bars represent $20 \mu \mathrm{m}$. Total duration: $59 \mathrm{~min}$.

Movie S2. Direct tumor cell killing mediated by a CAR4 T cell. C57BL/6 mice were sublethally irradiated and injected with E $\mu$-myc-DEVD tumor cells six days before treatment with $20 \times 10^{6}$ GFP-expressing CAR4 T cells. After 2 days, intravital imaging of the bone marrow was performed. The white circle highlights a tumor apoptotic event that is directly mediated by a cellular contact with a CAR4 $\mathrm{T}$ cell. $\mathrm{T}$ cells are shown in green, live tumor cells in white, and apoptotic tumor cells in blue. Scale bar represents $20 \mu \mathrm{m}$. Total duration: $60 \mathrm{~min}$.

Movie S3. Direct tumor cell killing mediated by a CAR8 T cell. C57BL/6 mice were sublethally irradiated and injected with E $\mu$-myc-DEVD tumor cells six days before treatment with $20 \times 10^{6}$ GFP-expressing CAR8 T cells. After 2 days, intravital imaging of the bone marrow was performed. The white circle highlights a tumor cell undergoing apoptosis following a direct cellular contact with a CAR8 $\mathrm{T}$ cell. $\mathrm{T}$ cells are shown in green, live tumor 
cells in white, and apoptotic tumor cells in blue. Scale bar represents $20 \mu \mathrm{m}$. Total duration: $59 \mathrm{~min}$.

Movie S4. Tumor B cell undergoing apoptosis without detectable contact with CAR4 T cells. C57BL/6 mice were sublethally irradiated and injected with E $\mu$-myc-DEVD tumor cells six days before treatment with $20 \times 10^{6}$ GFP-expressing CAR4 T cells. After 5 days, intravital imaging of the bone marrow was performed. The white circle highlights a tumor cell undergoing apoptosis without apparent contact with CAR4 T cells. T cells are shown in green, live tumor cells in white, and apoptotic tumor cells in blue. Scale bar represents $20 \mu \mathrm{m}$. Total duration: $59 \mathrm{~min}$.

\section{Movie S5. Tumor B cell undergoing apoptosis without detectable contact with CAR8 T} cells. C57BL/6 mice were sublethally irradiated and injected with E $\mu$-myc-DEVD tumor cells six days before treatment with $20 \times 10^{6}$ GFP-expressing CAR8 T cells. After 3 days, intravital imaging of the bone marrow was performed. The white circle highlights a tumor cell undergoing apoptosis without apparent contact with CAR8 T cells. T cells are shown in green, live tumor cells in white, and apoptotic tumor cells in blue. Scale bar represents $20 \mu \mathrm{m}$. Total duration: $60 \mathrm{~min}$.

Movie S6. WT CAR8 $T$ cells induce efficient tumor cell killing in the bone marrow. C57BL/6 mice were sublethally irradiated and injected with E $\mu$-myc-DEVD tumor cells six days before treatment with $10 \times 10^{6}$ GFP-expressing WT CAR8 T cells. After 5 days, intravital imaging of the bone marrow was performed. The white circles highlight multiple tumor cells that undergo apoptosis following a cellular contact with CAR T cells. T cells are shown in 
green, live tumor cells in white, and apoptotic tumor cells in blue. Scale bar represents $20 \mu \mathrm{m}$. Total duration: $65 \mathrm{~min}$.

Movie S7. IFN- $\gamma$-deficient CAR8 T cells are poorly cytotoxic at the tumor site. C57BL/6 mice were sublethally irradiated and injected with E $\mu$-myc-DEVD tumor cells six days before treatment with $10 \times 10^{6}$ GFP-expressing IFN- $\gamma$-deficient CAR8 T cells. After 5 days, intravital imaging of the bone marrow was performed. Despite numerous infiltrating CAR T cells, very few tumor apoptotic events have been recorded. T cells are shown in green, live tumor cells in white, and apoptotic tumor cells in blue. Scale bar represents $20 \mu \mathrm{m}$. Total duration: $59 \mathrm{~min}$. 